\section{Ankara Üniversitesi Eğitim Bilimleri Fakültesi Özel Eğitim Dergisi}

2022, 23(1), 23-51
ARAŞTIRMA

Gönderim Tarihi: 08.04.20

Kabul Tarihi: 12.03.21

Erken Görünüm: 11.04.21

\title{
Üstbilişi Geliştirmek İçin Düzenlenmiş Olan Öğretim Etkinliklerinin Öğretmen Adaylarının Üstbilişsel Farkındalıklarına Etkisinin İncelenmesi*
}

\author{
Gamze Kaplan $\mathbb{D} 1$
}

\author{
Çı̆̆l Aykut ${ }^{(\mathbb{D})_{2}}$
}

$\ddot{O} \mathbf{z}$

Giriş: $\mathrm{Bu}$ araştırmada öğretim elemanı tarafından dersin sunulmasında kullanılan üstbilişi düzenleyici öğretim etkinliklerinin öğretmen adaylarının üstbilişsel farkındalıklarının gelişimi ve akademik başarıları üzerindeki etkisi belirlenmeye çalışılmıştır. Uygulama özel eğitim öğretmenliği bölümü ikinci sınıf müfredatında yer alan Bütünleştirme dersinde yapılmıştır.

Yöntem: Araştırmada ön-test son-test kontrol gruplu yarı deneysel model kullanılmış, araştırmaya deney $(n=$ 20) ve kontrol $(n=20)$ olmak üzere toplam 40 öğrenci katılmıştır. Veriler Üstbilişsel Farkındalık Envanteri kullanılarak toplanmış, bağımsız örneklemler t-testi kullanılarak analiz edilmiştir.

Bulgular: Araştırma sonunda gruplar kendi içinde ön-test ve son-test puanları açısından karşılaştırıldığında ölçekten alınan toplam puan bakımından anlamlı fark oluşmadığı görülmüştür. Ölçeğin alt boyutları incelendiğinde deney grubunda planlamada alt boyutunda anlamlı fark bulunurken, diğer alt boyutlarda ise her iki grupta da ön-test ve son-test puanları arasında anlamlı bir farklılık oluşmadığı görülmüşsür. Gruplar birbiri ile karşılaştırıldığında ise ölçekten alınan toplam puan, açıklayıcı bilgi ve değerlendirme alt boyutları arasında gruplar arasında fark olduğu belirlenmiştir.

Tartışma: Yapılan uygulamanın üstbilişsel farkındalıkta bir değişime neden olduğu, öğretmen adaylarının üstbilişsel farkındalıklarının düşük düzeyde olduğu ve müdahale edilmedikçe gelişiminde ve kazanılmasında sınırlılıklar bulunduğu görülmüştür. Lisans düzeyinde Yükseköğretim Kurulunun ve mesleki yeterlilikler konusunda Milli Eğitim Bakanlığının yaptığı düzenlemelerde öz değerlendirme, öz düzenleme gibi beceriler öğretmenlik mesleği için birer gereklilik olarak belirtilmiştir. Bu nedenle tanımlamış olan yeterlilikleri karşılayacak düzenlemelerin işlevsel hale getirilmesine, öğretmen adaylarının seçimi ve atanması sırasında bu yeterliklerin karşılanmasına ilişkin alternatif değerlendirme yolları geliştirmesine ihtiyaç vardır.

Anahtar sözcükler: Üstbiliş, üstbilişsel farkındalık, özel eğitim, öğretmen yetiştirme, yükseköğretim.

Atıf için: Kaplan, G., \& Aykut, Ç. (2022). Üstbilişi geliştirmek için düzenlenmiş olan öğretim etkinliklerinin öğretmen adaylarının üstbilişsel farkındalıklarına etkisi. Ankara Üniversitesi Eğitim Bilimleri Fakültesi Özel Eğitim Dergisi, 23(1), 23-51. https://doi.org/10.21565/ozelegitimdergisi.715775

\footnotetext{
*Araştırma ilk yazarın Gazi Üniversitesi Eğitim Bilimleri Enstitüsünde, Prof. Dr. Çı̆̆ıl Aykut’un danışmanlığında hazırlanan doktora tezinden üretilmiştir.

${ }^{1}$ Sorumlu Yazar: Arş. Gör. Dr., Bülent Ecevit Üniversitesi, E-posta: kplngamze@gmail.com, https://orcid.org/0000-00023853-322X

2Prof. Dr., Gazi Üniversitesi, E-posta: cigil@gazi.edu.tr, https://orcid.org/0000-0002-0365-9930
} 


\section{Giriş}

İlk kez Flavell (1976) tarafından isimlendirilen ve bireyin bilişsel süreçlerinin farkında olması ve bilinçli olarak yapılandırması, depolanmış olan bilgiler arasından gerekli olanları bulması, düzenlemesi şeklinde tanımlanabilecek olan üstbiliş için farklı araştırmacılarca düşünme hakkında düşünme, biliş hakkında biliş gibi farklı isimlendirmeler de kullanılmıştır (Brown, 1987; Garner \& Alexander, 1989; Jacops \& Paris, 1987). Kavramın isimlendirilmesindeki bu çeşitlilik farklı şekillerde tanımlanmasına da yol açmıştır. Bu tanımlardan alanyazında sıkça karşılaşılanlar kişinin kendi bilişsel sistemine dair bilgisi ve kontrolü (Brown, 1987), bireyin düşünme süreçlerinin farkında olarak bu süreçleri değerlendirme ve düzenleme becerisi (Wilson, 2001), bilişsel stratejileri planlama, uygulama ve izlemeye ilişkin farkındalık (Panaoura \& Philippou, 2005) şeklinde sıralanabilir.

Üstbilişin tanımında olduğu gibi bileşenleri hakkında da farklı görüşler bulunmaktadır. Flavell (1979) üstbilişsel bilgi ve üstbilişsel deneyimler olmak üzere iki bileşenden söz etmiştir. Sonrasında araştırmalarda üstbilişsel bilgi ve üstbilişin düzenlenmesi (Hollingworth \& McLoughlin, 2001; Schraw \& Moshman, 1995); izleme, kendini düzenleme ve üstbilişsel bilgi (Flavell vd., 2002); üstbilişsel bilgi, bilişin düzenlenmesi ve üstbilişsel inanç (Lucangeli \& Cornoldi, 1997; Schoenfeld, 1987; Simons, 1996) gibi bileşenlerden söz edildiği görülmektedir. Üstbilişin bileşenleri ile ilgili ifadelerde de çeşitlilik görülse de bilişin bilgisi ve bilişin düzenlenmesi temel bileşenler olarak göze çarpar (Brown, 1987; Pintrich, 2002; Schraw \& Dennison, 1994; Schraw \& Moshman, 1995). Üstbilişsel bilgi, kişinin kendi bilişsel faaliyetleri hakkındaki bilgisi ya da biliş ile ilgili genel bilgi ve inançlarını ifade eder (Flavell, 1979; Schraw, 1998) ve tanımsal bilgi, işlemsel bilgi ve durumsal bilgiyi içerir (Brown, 1987; Jacobs \& Paris, 1987). Bilişin düzenlenmesi ise problem çözme sürecinde kişinin düşünme stratejilerini bilinçli olarak seçmesi, kullanması ve yönetmesidir (Santrock, 2001). Bilişin düzenlenmesi planlama, bilgiyi yönetme, izleme, hata düzeltme ve değerlendirme becerilerinden oluşur (Artzt \& Armour-Thomas, 1992; Schraw, 1998; Schraw \& Dennison, 1994).

Üstbilişin kuramsal temelinde yer alan bir diğer konu bireyin sözü edilen süreçle ilgili farkındalık düzeyidir. Üstbilişsel farkındalık olarak isimlendirilen bu kavram, belli bir durumda üstbilişsel bilginin alt bileşenleri ile ilgili (birey, strateji ve beceri) farkındalık geliştirmek için düşünme becerilerinin kullanımı (Ridley vd., 1992); kişinin kendi düşünmelerinin farkında olması (Paris vd., 1983) gibi farklı şekillerde tanımlanmaktadır. $\mathrm{Bu}$ farkındalık bireyin öğrenme sırasında mevcut bilgilerini incelemesini, hipotez kurmasını, tahminde bulunmasını ve bilgiyi edinmek için yapması gerekenler hakkında düşünmesini sağlayarak bireyin bilgiyi anlama, anlamlandırma, yansıtma ve karar verme gibi hedefe ulaşmayı sağlayan becerilerinin gelişimine de hizmet eder (Flavell, 1979; Gallagher, 1997). Böylelikle birey iç görü kazanır ve kendi öğrenme repertuarlarına ulaşarak öğrenmesini en üst düzeye taşıyabilir (Brown, 1994).

Üstbiliş ve üstbilişsel farkındalık yaşla birlikte artan gelişimsel bir süreç olmakla birlikte (Brown, 1987; Gardner \& Alexander, 1989; Schnider, 1998) üstbilişsel bilgi, beceri ve farkındalığın geliştirilmesi mümkündür. Farklı gelişim dönemlerinde, eğitim öğretim süreci içerisinde bu bilgi ve becerilerin kullanılması öğretilebilir (Brown, 1987; Gardner \& Alexander, 1989; Schnider, 1998). Eğitim-öğretimin diğer kademelerinde olduğu gibi üniversite de akademik başarı, bilişsel ve üstbilişsel yeteneklere bağlıdır. Bir üniversite öğrencisi, üstbilişsel becerilerde sınırlı ise görevin zorluk düzeyini belirleme, kavrama düzeyini izleme, öğrenme öncesinde plan yapma, başarı düzeyini belirleme, öğrenme materyalini tanıma, önceki bilgileri kullanma, hızlı karar verme alanlarında sorunlar yaşayacak (Gama, 2005), bilgiyi depolama tekniklerini kullanmakta ve süreçte aksama olduğu zaman bu teknikleri değiştirmekte zorlanacak, bu durum akademik başarısını olumsuz olarak etkileyebilecektir (Baker \& Brown, 1984; Hartman, 1998). Bu nedenle eğitim öğretimin her kademesinde sözü edilen beceri ve farkındalıkların desteklenmesine ihtiyaç vardır (Schraw, 1998).

Üstbiliş ve üstbilişsel farkındalık geliştirilebilmesi, bu sürecin uygulama alanına aktarımının sağlanabilmesi ve öğretim süreci ile uyumlu hale getirilebilmesi için ne tür planlamalar yapılabileceği merak edilen konulardan biridir. Alanyazında üstbilişsel farkındalığın geliştirilebilmesi için yapılan çalışmalarda iki yaklaşım benimsendiği görülmektedir. Bunlardan biri üstbilişsel stratejilerin doğrudan öğretimi, diğeri üstbilişi ve üstbilişsel farkındalığı destekleyici çevresel düzenlemeler yapılması ve sosyal ortamlar oluşturulmasıdır (Hartman, 1998; Lin, 2001).

Çevresel düzenlemelerde belirli bir konu alanına özgü sosyal ortamların oluşturulmasına ve öğrenenin kendi hakkındaki bilgisinin geliştirilmesini destekleyen uygulamalara vurgu yapılmaktadır (Lin, 2001). Konu alanına özgü bir öğrenme için sosyal bir ortam yaratılırken, etkinlikler ve yapılacak olan müdahaleler belirli bir konu ya da disiplinden kaynaklanan zorluklar dikkate alınarak planlanır. Bu türden tasarımların özelliği, öğrenme döngüsü içinde yerleşik ve amaç odaklı bir etkinlikler sistemi ve öğrenme kültürü oluşturmaktır. Etkinlikler bir 
ekosistem gibi birbirine bağlıdır ve öğrenme anlayışını derinleştirmek için tamamlayıcı destek sağlayarak birbirlerinden beslenirler (Brown \& Campione, 1996; Lin, 2001). Sosyal ortam yoluyla yapılan müdahalelerin tamamı, ders müfredatı ve günlük sosyal etkileşimlerin yeniden düzenlendiği, üstbilişsel etkinlikler içeren ve ihtiyaca göre değişebilen ortamlar oluşturabilmeyi amaçlar. Bu yolla üstbilişsel etkinlikler sistemi sağlanmasına ve gruptaki bireylere amaçlı etkinlik yapıları sağlanmasına çalışılır. Konu alanına özgü sosyal ortam tasarımlarında öğrenme hedefleri ve zorlukları etkinliklerin seçimini ve sırasını belirler. Sinerji sağlandığ 1 takdirde öğrenme etkinliklerinin sırası ve şekli değiştirilebilir (Brown \& Campione, 1996). Böylelikle bireylere gerek akademik gerek günlük yaşamlarının niteliğinin artmasına dönük öğrenme alışkanlıkları kazandırılmaya çalışılır (Hartman, 1988; Lin, 2001).

Kișinin öğrenme şeklinin farkında olması ve bu farkındalı̆̆ın gerek akademik gerekse günlük yaşama aktarılarak başarı düzeyinin artırılmasının mümkün olduğu göz önünde tutulursa üstbilişi geliştirmeye yönelik yapılan düzenlemelerin öğretmen yetiştirme alanına yansımaması halinde yapılan araştırmaların amacına sınırlı düzeyde ulaştığı düşünülebilir (Scheidler, 1994; Spillane \& Jennings, 1997). Geleneksel öğretmen yetiştirme anlayışında öğretmenlerin bilgi aktarımı açısından kaliteli öğreticiler olmasına dikkat edilmektedir. Günümüzde ise gerek teknolojik gelişmelerin gerekse bilgiye erişimin kolaylaşması nedeniyle bu bakış açısı yerini öğrenmeyi öğrenme, sinerji ve bilgi okuryazarlı̆ı kavramlarına bırakmakta ve bu kavramlar öğretmen eğitiminde önemli kalite göstergeleri olarak ön plana çıkmaktadır (Baştürk \& Yücel, 2004). Bu nedenle Bologna süreci kapsamında Türkiye Yüksek Öğretim Yeterlilikler Çerçevesi Öğretmen Yetiştirme ve Eğitim Bilimleri Alanı'nda temel alan yeterlikleri lisans düzeyi için bilgi, beceriler ve yetkinlikler yeniden tanımlanmış (Yükseköğretim Kurulu, [YÖK], 2011), Milli Eğitim Bakanlığının (MEB) 2017'de yayımladığı Öğretmen Mesleği Genel Yeterlilikleri'nde ise tüm öğretmenlik branşlarını kapsayan bütüncül bir anlayışla düzenlenmeler yapılmıştır. Düzenlemelerin odak noktası özdeğerlendirme yapabilen ve kendine öğrenme amacı belirleyerek bu amaç doğrultusunda planlama yapabilen, uygun stratejileri kullanabilen, kendini düzenleyebilen ve değerlendirebilen eğitimciler yetiştirilmesidir.

Özel Eğitim Öğretmenliği alanı değerlendirildiğinde ise lisans programlarının açılması ve yürütülme şekli ile MEB'in atama usulündeki uyuşmazlıklar nedeniyle bölümlerin açılmasında kullanılan kategorik modelden vazgeçilmiştir. Tüm özel eğitim branşları tek çatıda toplanmış ve seçmeli dersler bazında uzmanlaşmaya gidilmesine dönük bir uygulamaya başlanmıştır (YÖK, 2016). Ancak pek çok özel eğitim bölümünde gerek belirtilen alt alanların her birinde seçmeli ders açabilecek gerekse alan eğitimi derslerini verecek sayıda ve nitelikte öğretim elemanı bulunmamaktadır. Bir alanda uzmanlaşarak mezun olabilen öğretmen adayları ise uzmanlaşılan alana değil, bölüme göre atama yapılması nedeniyle uzmanlaştığı alandan farklı yetersizlik türleri ve düzeyleri ile karşılaşabilmektedir. Bu da öğretmenin sahip olması gereken yeterliliklerin sayısını ve özelliğini artırmaktadır. Çünkü bireysel farkl1lıkların en üst düzeyde olduğu öğrenciler ile çalışan özel eğitim öğretmenlerinin lisans eğitiminde aldıkları bilgileri yeniden düzenlemeleri, uyarlamaları, yeni bilgilere ulaşmaları, kendilerini değerlendirerek ihtiyaçlarını belirlemeleri ve öğrencilerinin ve içinde bulundukları koşulların gerekliliklerine göre problem çözebilmeleri beklenmektedir (Sontag vd., 1973).

$\mathrm{Bu}$ bağlamda öğretmen yetiştirme ve üstbiliş̧ bir arada değerlendirildiğinde, öğretmenlerin üstbiliş ile ilgili iki temel rolü olduğuna dikkat çekilmektedir. Bunlardan ilki öğrencilerin üstbilişsel bilgi ve becerilerinin geliştirilmesi; ikincisi öğretim, program ve değerlendirmede üstbilişsel etkinlikleri kullanılmasıdır (Hartman \& Stenberg, 1993). Öğretmen adaylarının üstbilişsel farkındalıklarının gelişmesi ise öğretmenlik eğitimi sırasında aldıkları derslerde üstbilişsel bilgi, beceri ve farkındalıklarının geliştirilmesine yönelik etkinliklere yer verilmesi ve ders içeriklerinin üstbilişsel gelişimi destekleyecek şekilde düzenlenmesi ile mümkün olabilir (Sezgin-Memnun \& Akkaya, 2012). Böylelikle yüksek düzeyde üstbilişsel farkındalığa sahip olarak mezun olmaları ise gerek kendi öğrenim hayatları gerekse mesleki yaşantılarını ve başarılarını etkileyecektir (Livingston, 1997; Marshall, 2003).

Yetişkin eğitimi ve öğretmen yetiştirme alanlarında Türkiye'de yapılan araştırmalar genel bir bakış açısıyla değerlendirildiğinde, çoğunluğunun farklı anketler yoluyla toplanan verilerin analizine dönük ilişkisel tarama türünde çalışmalar olduğu göze çarpmakta; oldukça büyük çalışma gruplarına da ulaşıldığı görülmektedir. Çalışmalarda akademik başarı, motivasyon, dil öğrenme ve problem çözme gibi bir alana özgü beceriler, mesleki alg1, zekâ, özyeterlik, çoklu zekâ kuramı, bilimsel tutum, pedagojik formasyon, sınıf düzeyi ve demografik özellikler gibi değişkenler ile üstbiliş arasındaki ilişkinin incelendiği belirlenmiştir. Deneysel desenlerle yapılan çalışmalarda ise tek bir üstbilişsel stratejinin doğrudan öğretiminin akademik başarıya etkisinin belirlenmesine (Pilten, 2008), farklı öğretim stratejilerinin öğretimde kullanılmasının (problem çözme, yansıtıc öğrenme, eleştirel düşünme vb.) üstbilişisin gelişimine etkisinin incelenmesine (Esendemir, 2011; Yangın, 2014; Yürük vd., 2011) ve öğretimsel uyarlamaların üstbilişin gelişimine etkisine odaklanıldığı görülmektedir (Duman, 2013). Yurt dışında yapılan araştırmalarda da benzer bir durumla karşılaşılmıştır. Bunların dışında tıp fakültesinde teorik bir dersin 
içeriğinde üstbilişsel öğretim etkinliklerine yer verildiği bir çalışmaya (Gönüllü, 2010) ve fen bilgisi öğretmenliğinde yer alan laboratuvar dersinde üstbilişsel etkinlikler aracilığıyla öğretim yapılmış olan (Çakır, 2011) bir çalışmaya ulaşılmıştır. Bu çalışmaların ikisinde de yetişkin eğitiminde üstbilişin gelişimini destekleyecek öğretim etkinlikleri hazırlanarak bu etkinliklerin dersin işlenişinde kullanıldığı görülmüşsür. Yurt dışında yapılan araştırmalarda da benzer bir durumla karşılaşılmış̧ır. Ancak üstbilişin gelişimini destekleyecek öğretim etkinliklerinin bir dersin tamamında gömülü olarak kullanıldığı bir çalışmaya ulaşılamamıştır.

$\mathrm{Bu}$ araştırmada öğretmen adaylarına mesleki yaşamlarına başlamadan önce üstbilişsel öğrenme kültürüne dönük yeterliliklerin kazandırılmasına çalışılmıştır. Böylelikle gerek kişisel gerek mesleki anlamda üstbilişsel düşünme becerilerinin desteklenmesine hizmet edeceği düşüncesiyle çevrenin üstbilişsel farkındalığı artıracak şekilde düzenlenmesine dayanan bir öğretim planlaması yapılmıştır. Yapılan planlamada öğretim etkinlikleri ders içeriğinin tamamını kapsayacak ve üstbilişsel farkındalığı destekleyecek şekilde seçilerek ders müfredatı içine yerleştirilmiş̧tir. Planlama sonrasında öğrenme etkinlikleri ögretim elemanı tarafindan dersin sunulmasında kullanılarak öğretmen adaylarının üstbilişsel farkındalık düzeylerinin gelişiminin desteklenmesi amaçlanmış, öğretim etkinliklerinin öğretmen adaylarının üstbilişsel farkındalıklarının gelişimi üzerindeki etkilerinin incelenmesine çalışılmıştır. Bu amaçtan hareketle yazılmış olan araştırma soruları aşağıda verilmiştir:

1. Üstbilişsel farkındalığı geliştirmek için düzenlenmiş olan öğretim etkinliklerinin öğretmen adaylarının üstbilişsel farkındalıklarına etkisi var mıdır?

1.1. Üstbilişsel farkındalığı geliştirmek için düzenlenen öğretim etkinliklerinin uygulandığı deney grubu ile anlatım yönteminin uygulandığı kontrol grubu arasında üstbilişsel farkındalık envanterinden aldıkları ön-test ve son-test puanları açısından anlamlı fark var mıdır?

1.2. Üstbilişsel farkındalığı geliştirmek için anlatım yönteminin uygulandığı kontrol grubunda yer alan öğrencilerin üstbilişsel farkındalık envanterinden aldıkları ön-test puanları ile son-test puanları arasında anlamlı fark var midır?

1.3. Üstbilişsel farkındalığı geliştirmek için düzenlenen öğretim etkinliklerinin uygulandığı deney grubunda yer alan öğrencilerin üstbilişsel farkındalık envanterinden aldıkları ön-test puanları ile sontest puanları arasında anlamlı fark var midır?

2. Üstbilişsel farkındalığı geliştirmek için düzenlenen öğretim etkinliklerinin uygulandığı deney grubu ile anlatım yönteminin uygulandığı kontrol grubu arasında akademik başarı düzeyleri açısından anlamlı fark var midır?

Araştırmanın genel anlamda yükseköğretimde ve öğretmen yetiştirme alanında yer alan derslerin üstbilişsel beceri ve farkındalıkları destekleyecek şekilde düzenlenmesine ve planlanmasına dönük fikir verebilmesi, YÖK ve MEB tarafindan belirlenen mesleki standartlar boyutunda öğretmen yetiştirme ile ilgili alanyazına katkı sağlanabilmesi açısından önemli olduğu düşünülmektedir.

\section{Yöntem}

Araştırmada ön-test son-test kontrol gruplu yarı deneysel model kullanılmıştır. Deneysel modeller, nedensonuç ilişkilerini belirlemeye çalışmak amacıyla araştırmacının doğrudan kontrolü altında, gözlenmek istenen verilerin üretildiği modellerdir. Deneysel modellerde bağımsız değişkenlerin bağımlı değişkenleri nasıl etkilediği görülmeye çalışılır. Yarı deneysel modelde tam deneysel modelden farklı olarak, kontrol ve deney gruplarının tesadüfen değil de ölçütlerle seçilmesi söz konusudur. Araştırmacı mevcut gruplar arasından birini deney diğerini kontrol grubu olarak belirler. Bu nedenle araştırmacının zaman kaybetmeden var olan grup üzerinde araştırma yapabilmesini olanaklı kılar (Karasar, 2012). Ancak grupların denk olmama olasılığının ortadan kaldırılabilmesi için deneysel süreç başlamadan önce her iki gruba da ön-test uygulanarak denklik sağlanmalıdır (Creswell, 2009).

$\mathrm{Bu}$ araştırmada da uygulamanın yapılacağı ders belirlendikten sonra araştırmacı zaman kazanabilmek için var olan grupla çalışmayı tercih etmiştir. Araştırmaya başlanabilmesi için Bülent Ecevit Üniversitesi İnsan Araştırmaları Etik Kurulundan gereken izinler alındıktan sonra (30.11.2017; protokol no: 271) grup deney ve kontrol grubu olarak ikiye ayrılmıştır. Her iki gruba da ön-test uygulanarak grupların denkliği sağlanmıştır. Araştırmanın bağımlı değişkenlerini öğrencilerin üstbilişsel farkındalık düzeyleri ve ders başarısı oluşturmaktadır. Bağımsız değişkeni ise üstbilişsel farkındalığı geliştirmek için sunulan öğretim etkinlikleridir. 


\section{Evren ve Örneklem}

Çalışmada katılımcı grubun oluşturulmasında tesadüfi örneklem yaklaşımının kullanılamaması nedeniyle amaçlı örnekleme yöntemlerinden kolay ulaşılabilirlik durum örneklemesi kullanılmıştır. Kolay ulaşılabilirlik durum örneklemesi ise araştırmacıya hız ve pratiklik kazandırır. Bu örnekleme yönteminde araştırmacı, yakınında olan ve erișilmesi kolay bir durumu seçer (Yıldırım \& Șimșek, 2005). Bu araștırmada öğretmen adaylarına erişebilirlik durumu nedeniyle amaçlı örneklem içinde kolay ulaşabilirlik üzerinden katılımcılar tespit edilmiştir.

Araştırma, Bülent Ecevit Üniversitesi Ereğli Eğitim Fakültesi Özel Eğitim Bölümü 2. sınıfına devam eden öğrenciler ile yürütülmüştür. Grup deney $(n=20)$ ve kontrol grubu $(n=20)$ olarak 2'ye ayrılmış ve gruplarda yer alacak öğrenciler yansız atama ile belirlenmiştir. Atama sırasında öğrencilerin numaraları yazılıp kura çekilmiştir. Öğrencilerin gruplara göre cinsiyetlerinin dağılımları ve uygulamanın başladığı döneme kadarki akademik ortalamalarına iliş̧in bilgi Tablo 1'de gösterilmiştir.

\section{Tablo 1}

Cinsiyet Dağıllmları ve Akademik Ortalama

\begin{tabular}{ccccc}
\hline \multicolumn{1}{c}{ Gruplar } & $n$ & En yüksek ortalama & En düşük ortalama & Grup ortalaması \\
\hline Deney grubu & $14 \mathrm{~K}, 6 \mathrm{E}$ & 3.60 & 2.09 & 2.86 \\
Kontrol grubu & $10 \mathrm{~K}, 10 \mathrm{E}$ & 3.51 & 2.17 & 2.89 \\
\hline
\end{tabular}

Not: $\mathrm{K}=$ kadin; $\mathrm{E}=$ erkek.

\section{Veri Toplama Araçları}

Araştırmada Üstbilişsel Farkındalık Envanteri ve araştırmacı tarafından geliştirilen Ders Başarı Testi kullanılmıştır.

\section{Üstbilişsel Farkındalık Envanteri (ÜFE)}

Öğretmen adaylarının üstbilişsel farkındalık düzeylerini belirlemek için Schraw ve Dennison (1994) tarafından geliştirilen Biliş̧̈tesi (Üstbilişsel) Farkındalık Envanteri (ÜFE) (Metacognitive Awareness InventoryMAI) kullanılmıştır. Envanter yetişkinlerin üst bilişsel düzeylerini belirlemede kullanılmaktadır. ÜFE, 52 maddeden oluşmaktadır. (1) Hiçbir zaman (2) Nadiren (3) Sık sık (4) Genellikle ve (5) Her zaman şeklinde 5'li Likert tipi bir derecelendirmeye sahiptir. Envanterden alınabilecek en düşük puan 52, en yüksek puan ise 260'tır.

Envanterin Türkçeye uyarlaması, geçerlik ve güvenirlik çalışması Akın ve diğerleri (2007) tarafından gerçekleştirilmiş. Yapı geçerliği olarak açımlayıcı faktör analizi ile uyum geçerliği yapılmıştır. Güvenirlik için ise iç tutarlılık ve test-tekrar test katsayıları incelenmiştir. Dilsel eşdeğerlik bulguları ölçeğin orijinal ve uyarlanan form puanları arasındaki ilişsinin .93 olduğunu göstermiştir. Yapılan açımlayıcı faktör analizi sonucunda bilişin bilgisi ve bilişin düzenlenmesi temel boyutları altında yer alan sekiz alt boyut elde edilmiştir. Bu alt boyutlar açıklayıcı bilgi, işlemsel bilgi, durumsal bilgi, planlama, izleme, değerlendirme, hata ayıklama ve bilgi yönetmedir. Uyum geçerliği çalışması iki ölçek arasında .95 korelasyon olduğunu ortaya koymuştur. Madde analizi sonucunda alt ölçeklerin madde-test korelasyonlarının .35 ile .65 arasında değiştiği görülmüştür. Envanterin iç tutarlılık ve test-tekrar test güvenirlik katsayıları .95 olarak bulunmuştur.

Bilişe İlişskin Bilgi. Envanterin ilk alt boyutu bilişe ilişkin bilgi, açıklayıcı bilgi, işlemsel bilgi ve durumsal bilgiyi kapsamaktadır. Açıklayıcı bilgi 8, işlemsel bilgi 4, durumsal bilgi 5 maddeden oluşmaktadır.

Bilișin Düzenlenmesi. İkinci alt boyut olan bilişin düzenlenmesi boyutunda ise planlama, izleme, değerlendirme, hata ayıklama ve bilgiyi yönetme ölçülmektedir. Planlamada 7, izlemede 8 , değerlendirmede 6 , hata ayıklamada 5, bilgiyi yönetmede ise 9 madde yer almaktadır.

\section{Ders Bașarı Testi}

Başarı testleri geliştirilirken testin ölçme gücünün belirlenebilmesinde madde güçlüğü dikkate alınmaktadır. Ancak kişi sayısının 25 'in altına düştüğü gruplarda güçlük indeksi hesaplanması halinde elde edilecek sonucun büyük ölçüde çarpık olduğu, başarı düzeyi ölçülürken test maddelerinin dağılımının \%20'sinin kolay, $\% 60$ ’ının orta, $\% 20$ 'sinin zor düzeyde güçlüğe sahip olmasının sağlanmasının testin yordama gücünü artıracağı belirtilmektedir. Bu bağlamda sorular hazırlanırken şans faktörünün kontrol altına alınmasına ve soru ifadelerinin uygunluğuna dikkat edilmesi önerilmektedir (Şencan, 2005). Bu araştırmada öğrencilerin öğrenme durumlarını değerlendirmek amacıyla araştırmacı tarafından kazanımlara yönelik sorular yazılarak vize sınavı için 50, final sınavı için 60 soruluk havuzlar oluşturulmuştur. Test geliştirilirken ölçümün iyileştirilebilmesi için şans faktörünün azaltılması amacıyla 5 seçeneğe yer verilmiş, soru köklerinin ve madde ifadelerinin açık ve anlaşılabilir 
olmasının sağlanması içinse uzman görüşüne başvurulmuştur. Görüşüne başvurulan üç uzman özel eğitim alanında doktora derecesine sahip ve dersi daha önce vermiş olan uzmanlardır. Oluşturulan soruların uzmanlarca dilanlatım, yazım ve bilişsel taksonomi ve zorluk bakımından incelenmesi sağlanmıştır. Bilişsel taksonomi ve soru zorluk dağılımlarının önden dağılımı kontrol altına alınmıştır. Uzmanlardan gelen geri bildirimler sonrasında düzenlemeler yapılarak sorular taksonomik düzeylerine göre kolay-orta-zor olarak üç gruba ayrılmıştır. Sorular güçlük dağılımında ayırt edicilikleri bakımından değerlendirilerek \%20-\%60-\%20 dağılımı ile ön-test son-test içine yerleştirilmiştir.

\section{Uygulama}

Araştırma üç aşamadan oluşmaktadır. İlk aşama olan hazırlık aşamasında uygulamanın yapılacağı ders ve grup belirlenmiş, ölçme araçları seçilmiş ve ders içeriği geliştirilmiştir. İkinci aşama olan uygulama aşamasında ön-test verilerinin toplanması ve uygulamanın yapılması yer almaktadır. Son aşama olan uygulama sonrasında ise son-test verileri toplanmış, görüşmeler tamamlanmıştır. Süreç ile ilgili temel işleyiş Şekil 1'de kısaca özetlenmiştir. Ardından uygulamaya hazırlık sürecinde yapılanlar ile ilgili bilgiler detaylı bir şekilde açıklanmıştır.

\section{Şekil 1}

Araştırmanın Aşamaları

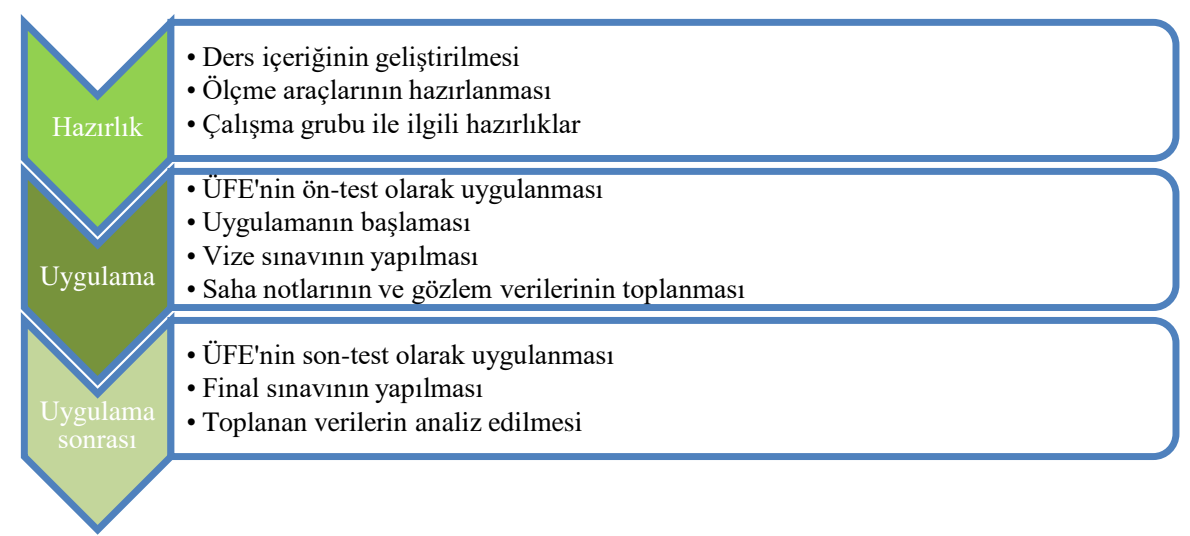

Not: ÜFE = Üstbilişsel Farkındalık Envanteri.

\section{Ders İçeriğinin Geliştirilmesi}

Hazırlık aşamasının ilk kısmında yer alan ders içeriğinin geliştirilmesi, konu başlıkları ve kazanımların yazımı ile uygulanacak öğrenme-öğretme etkinliklerinin seçimi olmak üzere iki aşamadan oluşmaktadır. Kazanımların yazım süreci aşağıda özetlenmiş ve Şekil 2'de gösterilmiştir.

\section{Şekil 2}

Konu Başlıkları ve Kazanımların Yazım Aşamaları

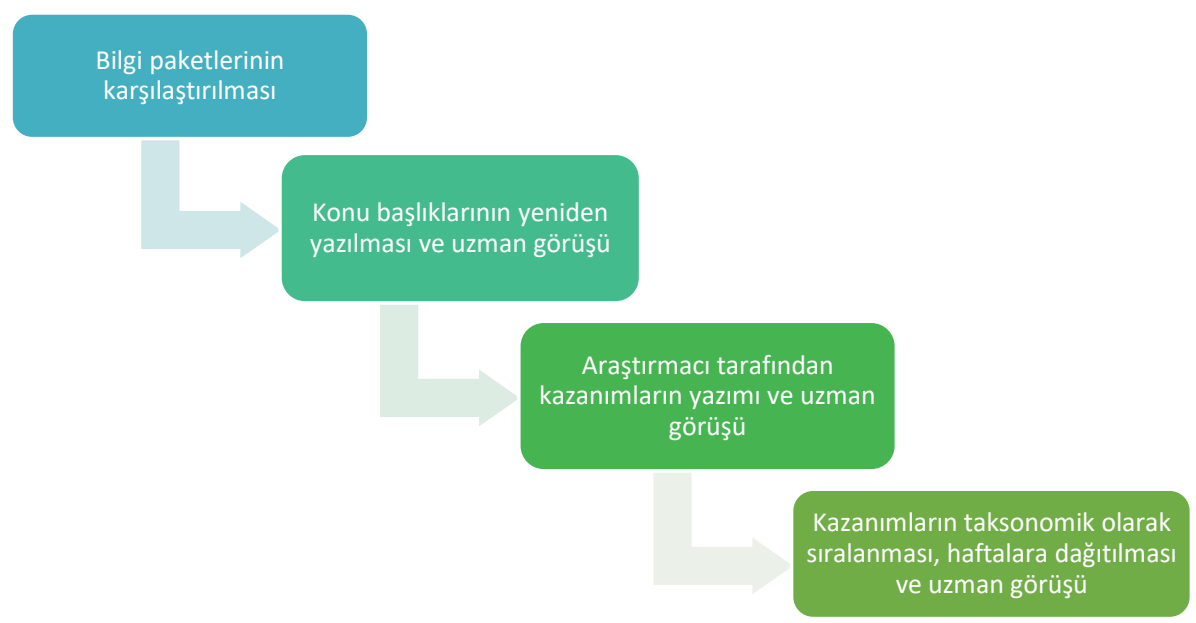


Konu Başıkları ve Kazanımların Yazımı. Ders içeriğinin ve kazanımların belirlenmesi amacıyla önce Özel Eğitim Öğretmenliği programı olan üniversitelerin bilgi paketlerine ulaşılmıştır. Bilgi paketlerinde konu başlıklarının yanı sıra dersi veren öğretim elemanlarınca hazırlanmış olan kazanımlar belirlenmiş̧ir. Bilgi paketlerinde yer alan kazanımlar incelendiğinde, kazanımların çoğunun bir kazanımda bulunması gereken özelliklere sahip olmadığı, dersin içeriği ile örtüşmediği ve eksik yazıldığı görülmüștür. Araştırmacı tarafından dersin yürütülmesinde kullanılan kaynak kitaplardan ve alanyazından faydalanılarak konu başlıkları yazılmış ve dersi daha önce yürütmüş olan uzmanlardan görüş alınmıştır. Konu başlıklarının belirlenmesinin ardından bu başlıklara uygun kazanımlar yazılarak taksonomik olarak sıralanmıştır. Konunun özelliğine, içeriğine ve işlenmesi için ihtiyaç duyulan süreye göre haftalara dağıtılarak tekrar uzman görüşüne gönderilmiştir. Gereken düzeltmeler yapıldıktan sonra konu başlıklarına ve kazanımlara son hali verilmiştir.

Öğrenme-Öğretme Etkinliklerinin Seçimi. Dersin kazanımların belirlenmesinin ardından öğretmeöğrenme etkinlikleri ve sınama durumları planlanmaya başlanmıştır. Etkinlikler yazılırken alanyazında yapılan çalışmalar incelenmiştir (Bielaczyc vd., 1994; Brown \& Campione, 1996; Hacker vd., 1998; Lin \& Lehman, 1999). Yürütülmüş olan araştırmada da belirli bir strateji öğretmek yerine içerik içine yerleştirilmiş olan etkinlikler aracılığıyla dersin günlük rutini içinde bir yandan alan bilgisi verilirken bir yandan da üstbilişsel farkındalığın artırılmasına dönük bir planlama yapılmaya çalışılmıştır. Etkinliklerin seçimi ve planların yazılması sırasında izlenen aşamalar Şekil 3'te gösterilmiş̧ir.

\section{Şekil 3}

Etkinliklerin Seçimi ve Planların Yazılması

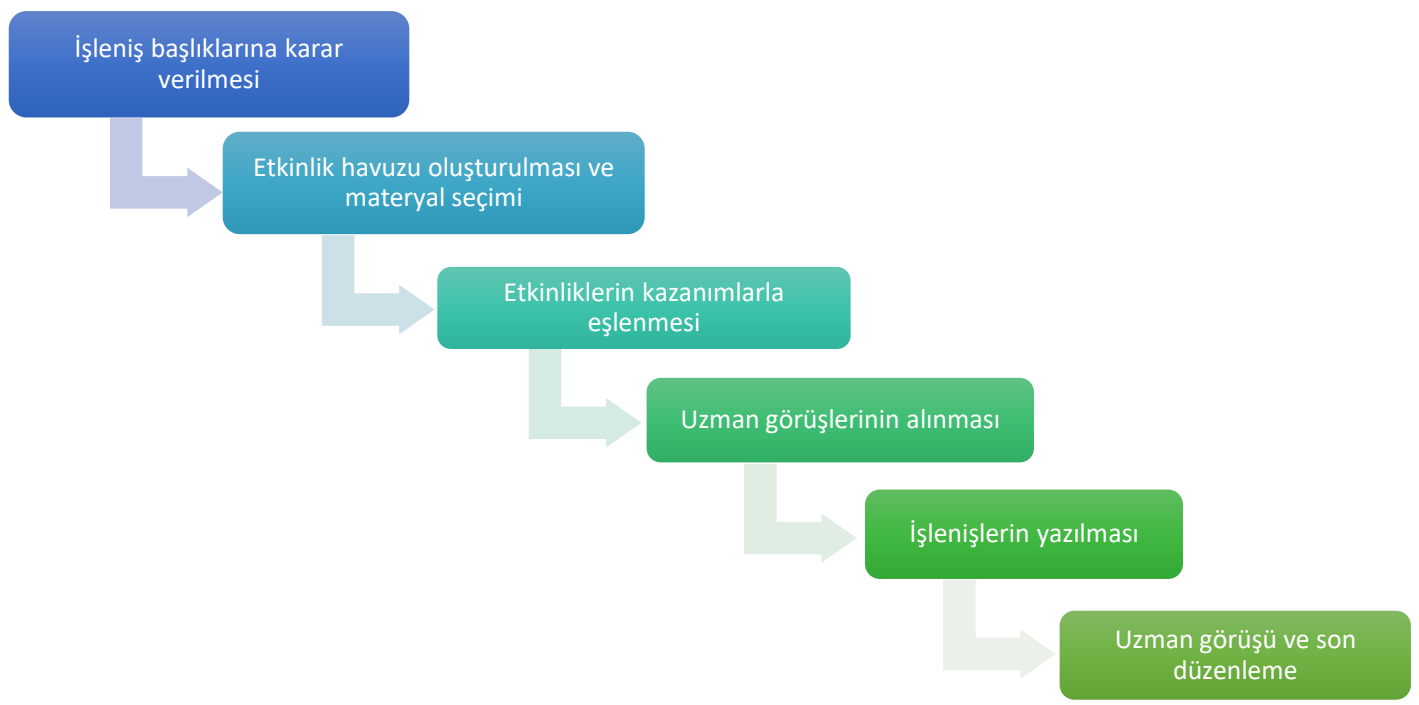

İşlenişler yazılmadan her birinde yer alması gereken bölümlere ilişkin uzman görüşü alınmıştır. Görüşler doğrultusunda her planda, ünite adı, konu adı, o ders kapsamında kazandırılması planlanan kazanımlar, öğretim yöntem, teknik ve stratejileri, materyaller, dikkati çekme ve hedeften haberdar etme etkinliklerine yer verilen bir tanıtıcı bölüm; ders sırasında yaşanan sürecin ve etkinliklerin kullanımının açıklandığı işleniş bölümü ve ders sonlandırılması için gözden geçirme ve değerlendirme etkinliklerinin yer aldığı bitiriş bölümünün yer almasına karar verilmiştir.

Ardından daha önce belirlenmiş ve uzman görüşü alınmış olan kazanımlara uygun öğrenme-öğretme etkinliklerinin belirlenmesine başlanmıştır. Öncelikle alanyazında benzer çalışmalarda kullanılan etkinliklerden bir havuz oluşturulmuştur. Oluşturulan etkinlik havuzundan planlarda kullanılmak üzere beyin firtınası, gruplama/örgütleme, özetleme, çıkarım yapma, bilgi birimlerini belirleme, etiketleme, içerik yapılandırma, kendini izleme, okuduğunu anlama, anlamlandırma, yüksek sesli düşünme, kendi kelimeleriyle açıklama, şematik düzenleyici oluşturma ya da doldurma, akran değerlendirmesi, kendini izleme, eklemleme, ön bilgileri harekete geçirme etkinlikleri seçilmiştir. $\mathrm{Bu}$ etkinlikler kazanıma uygunluk, uygulama sırasında kullanılabilirlik, anlaşılırlık, kazandırılması planlanan beceriye uygunluk ve amaca en üst düzeyde ulaşmaya hizmet etme özelliklerini taşıdıkları düşünülerek tercih edilmiştir. Toplam 11 haftalık işleniş hazırlanmış, alanyazında ulaşılan etkinliklerden oluşturulan havuzdan işlenişte yer alan her bir kazanım için uygun olanı seçilmiştir. Etkinliklerin becerilere göre dağılımı Şekil 4'teki gibidir. 
Etkinlik seçimleri tamamlandıktan sonra öğretimde kullanılacak materyaller belirlenmiştir. Öğretim materyali olarak çalışma kâğıtları, resimler, videolar, sunumlar, grafik, şematik düzenleyici ya da tabloların şablonları, örnek olay senaryoları, çeşitli yazılı materyaller hazırlanmıştır. Hangi etkinliğin ve materyalin uygulanacağına karar verilirken kazanımın taksonomik düzeyi ve etkinliğin kazanım için uygulanabilirliği dikkate alınmaya çalışılmıştır. Her dersin sonrasında öğrencilere verilecek ödevler ya da değerlendirme süreçleri de yine etkinliğin ve kazanımın özelliğine göre planlanmaya çalışılmıştır.

Ardından bir önceki aşamada hazırlanmış ve haftalara dağıtılmış olan kazanımlar etkinlikler ile birleştirilerek işlenişler yazılmaya başlanmıştır. İşlenişler, değerlendirilmek üzere üç alan uzmanına gönderilmiştir. Uzmanlardan gelen dönütlerden sonra araştırmacı ayrıca eğitim programları ve öğretimi uzmanı ile görüş̧erek işlenişlerde, etkinliklerde ve materyallerde yeniden düzenleme yapmıştır. Bu düzenlemenin ardından üstbiliş çalışmaları konusunda deneyimli bir başka uzman ile etkinliklerin isimlendirilmesi ve kullanımı konusunda tekrar çalışılmıştır. Tüm görüşler ve çalışmalar sonunda işlenişlere son hali verilerek uygulamaya hazır hale getirilmiştir.

\section{Şekil 4}

\section{Etkinliklerin Becerilere Göre Dă̆ılımı}

Ön bilgiler harekete geçirme
$\quad$ etkinlikleri
- Soru-cevap
- Fikir taraması
- Örnek olay
- Beyin firtınası

Bilgiyi çağırma, yapılandırma,
$\quad$ ilişki kurma etkinlikleri
- Kendi kelimeleriyle açıklama
- Hatırlatıcılar
- Iccerik yapılandırma
- Gruplama
- Örgütleme
- Etiketleme
- Özetleme
- Çıarım yapma

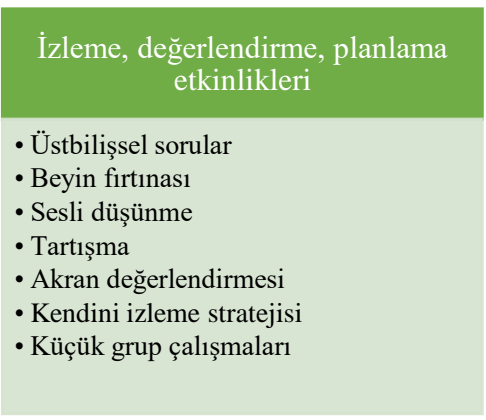

Hazırlık aşamasında sözü edilen tüm bu çalışmalar tamamlandıktan sonra araştırmanın uygulama aşamasına geçilmiştir. Uygulama aşamasının ilk haftasında deney ve kontrol gruplarına ön-test olarak ÜFE uygulanmıştır. Ardından her iki grupta da dersler işlenmeye başlamıştır. Deney grubunda üstbilişi geliştirmek amacıyla düzenlenen öğretim etkinlikleri kullanılmıştır. Kontrol grubunda ise soru-cevap etkinlikleri, Powerpoint sunumu gibi etkinliklerden yararlanılarak anlatım yöntemi ile dersler işlenmiştir. Uygulamanın altıncı haftasından sonra hazırlanmış olan ders başarı testlerinden ilki kullanılarak vize sınavları yapılmıştır. Sınavlardan sonraki beş hafta boyunca dersler yine belirtildiği şekilde her iki grupta da devam etmiştir. 11 haftalık sürecin sonunda uygulama aşaması tamamlanmıştır.

Çalışmanın son aşamasında ise uygulama sonrası verilerin toplanması amacıyla ÜFE her iki grupta da son-test olarak uygulanmış ve ders başarı testinin ikincisi kullanılarak final sınavları yapılmıştır. Toplanan veriler analiz edilerek uygulama sonrası aşama da tamamlanmıştır.

\section{Uygulama Güvenirliği}

Araştırmanın bağımsız değişkeninin yapılan planlamaya uygun olarak gerçekleştirilip gerçekleştirilmediğini belirlemek amacıyla uygulama güvenirliği hesaplanmıştır. Uygulama güvenirliğinin hesaplanabilmesi için işlenen dersler video ile kaydedilmiştir. Öğretimin değerlendirilebilmesi için bir form geliştirilmiş ve tüm kayıtlar arasından rastgele seçilen \%30'luk kısım araştırmacı dışında doktorasını tamamlamış bir alan uzmanı tarafından değerlendirilmiş̧tir. Hesaplama sırasında [uygulamada gözlenen doğru davranış / gözlenmesi gereken doğru davranış x 100] formülü kullanılmıştır. Çalışmanın uygulama güvenirliği Tablo 2'de görüldüğü gibi \%94 olarak hesaplanmış olup, bu değer iyi olarak nitelendirilmektedir (House vd., 1981).

\section{Tablo 2}

Uygulama Güvenirliği (UG) Sonuçları

\begin{tabular}{llc}
\hline \multicolumn{1}{c}{ Hafta } & \multicolumn{1}{c}{ Konu içeriği } & UG yüzdesi \\
\hline 3.Hafta & Özel gereksinimli çocuklar ve kaynaştırma & 91 \\
4.Hafta & Değerlendirme ve Bireyselleştirilmiş Eğitim Programı & 96 \\
7.Hafta & Öğretimin uyarlanması & 93 \\
9.Hafta & Sinıfta davranış kontrolü & 95 \\
Ortalama & & 93.75 \\
\hline
\end{tabular}




\section{İç ve Dış Geçerlik}

Araştırmada iç geçerliği sağlayabilmek için katılımcılar deney ve kontrol gruplarına rastgele alınmıştır. Her grupta 20 öğrenci yer almış, fiziksel koşulların dengelenmesi amacıyla dersler aynı sınıfta yapılmıştır. Dersler birbirine yakın sürelerde tamamlanmaya çalışılmış, sürenin tehdit oluşturması önlenmeye çalışılmıştır. İki gruptaki tüm öğrenciler ön-test ve son-teste katılmış, ders başarı testini tamamlamıştır. Böylelikle eksik ya da kayıp veri olması önlenmiştir. Katılımcılara deneysel süreçte olduklarına ve hangi grupta yer aldıklarına ilişkin herhangi bir bilgi verilmemiştir. Her iki grupta da dersleri araştırmacı yürütmüştür. Dersler farklı günlerde yapılmış, derste kazandırılması planlanan kazanımlar ve bu sırada kullanılacak öğrenme öğretme etkinliklerine ilişkin notlar ve işlenişlere bağlı kalınmasına çalışılmıştır. Sıralanan bu faktörlerin kontrol altında tutulmasına dikkat edilerek bir grubun sonucu etkileyecek şekilde aşırı yarar sağlaması önlenmeye çalışılmıştır.

Dış geçerlik araştırmada ulaşılan bulguların farklı gruplara ve ortamlara genellenebilirliğini ifade eder (Karasar, 2012). Bu araştırmanın sonucunda deney grubu ile kontrol grubunun ön-test ve son-test verilerinde bağımlı değişken açısından deney grubu lehine anlamlı fark oluştuğu görülmüştür. Çalışmada katılımcılar deney ve kontrol gruplarına rastgele atanarak çalışmanın bulgularının benzer gruplara genellenebilirliği sağlanmaya çalışılmıştır.

\section{Verilerin Analizi}

Araştırma sonunda elde edilen verilerin doğru analiz edilebilmesi için öncelikle verilerin dağılımına bakılmıştır. Yapılan analizde verilerin normal dağılım gösterdiği görülmüştür. Bu nedenle parametrik testler kullanılarak veriler analiz edilmiştir. Araştırmada toplanan verilerin analizinde bağımlı örneklemler $\mathrm{t}$ testi, bağımsız örneklemler $\mathrm{t}$ testi, ortalama, standart sapma ve frekans kullanılmıştır.

\section{Bulgular}

Bu bölümde üstbilişsel farkındalığı geliştirmek için öğretim elemanı tarafından düzenlenen ve dersin içeriğine yerleştirilen öğretim etkinliklerinin öğretmen adaylarının üstbilişsel farkındalık düzeylerine etkisinin belirlenmesi amacıyla yapılmış olan araştırma sırasında toplanan verilerin uygun yöntem ve teknikler kullanılarak analiz edilmesiyle ulaşılan bulgular araştırma soruları kapsamında sırasıyla açıklanmaya çalışılmıştır.

\section{Deney ve Kontrol Grubunun ÜFE’den Aldıkları Ön-test ve Son-test Puanlarının Karşılaştırılması}

Araştırmanın ilk sorusu deney ve kontrol grubunun ÜFE'den aldıkları ön-test ve son-test puanları arasında fark olup olmadığının belirlenmesidir. Uygulamaya başlamadan önce deney ve kontrol grubunda bulunan öğrencilerin üstbilişsel farkındalık düzeyleri bakımından benzer özelliklerde olup olmadıklarının belirlenebilmesi amacıyla her iki gruba da ÜFE ön-test olarak uygulanmıştır. Grupların ön-testten aldıkları puanlar ilişkisiz örneklemler t-testi ile karşılaştırılmıştır (Tablo 3).

Tablo 3

Deney ve Kontrol Grubunun ÜFE'den Aldıkları Ön-test Puanları t-Testi Sonuçları

\begin{tabular}{|c|c|c|c|c|c|c|c|c|}
\hline Alt boyutlar & Grup & $n$ & $\bar{X}$ & Ortalamalar arası fark & $S S$ & $S D$ & $t$ & $p$ \\
\hline Açıklayıcı bilgi & $\begin{array}{c}\text { Deney } \\
\text { Kontrol }\end{array}$ & $\begin{array}{l}20 \\
20\end{array}$ & $\begin{array}{l}30.75 \\
28.70\end{array}$ & 2.05 & $\begin{array}{l}3.41 \\
4.95\end{array}$ & 38 & 1.524 & .136 \\
\hline İşlemsel bilgi & $\begin{array}{l}\text { Deney } \\
\text { Kontrol }\end{array}$ & $\begin{array}{l}20 \\
20\end{array}$ & $\begin{array}{l}13.70 \\
14.60\end{array}$ & -.90 & $\begin{array}{l}2.57 \\
1.70\end{array}$ & 38 & -1.304 & .200 \\
\hline Durumsal bilgi & $\begin{array}{l}\text { Deney } \\
\text { Kontrol }\end{array}$ & $\begin{array}{l}20 \\
20\end{array}$ & $\begin{array}{l}18.65 \\
19.35\end{array}$ & -.70 & $\begin{array}{l}2.88 \\
2.68\end{array}$ & 38 & -.794 & .432 \\
\hline Planlama & $\begin{array}{l}\text { Deney } \\
\text { Kontrol }\end{array}$ & $\begin{array}{l}20 \\
20\end{array}$ & $\begin{array}{l}23.85 \\
24.85\end{array}$ & -1.00 & $\begin{array}{l}4.52 \\
2.77\end{array}$ & 38 & -.843 & .405 \\
\hline İzleme & $\begin{array}{l}\text { Deney } \\
\text { Kontrol }\end{array}$ & $\begin{array}{l}20 \\
20\end{array}$ & $\begin{array}{l}27.70 \\
27.10\end{array}$ & .60 & $\begin{array}{l}5.19 \\
4.20\end{array}$ & 38 & .402 & .690 \\
\hline Değerlendirme & $\begin{array}{l}\text { Deney } \\
\text { Kontrol }\end{array}$ & $\begin{array}{l}20 \\
20\end{array}$ & $\begin{array}{l}21.45 \\
21.00\end{array}$ & .45 & $\begin{array}{l}3.83 \\
2.86\end{array}$ & 38 & .421 & .676 \\
\hline Hata ayıklama & $\begin{array}{c}\text { Deney } \\
\text { Kontrol }\end{array}$ & $\begin{array}{l}20 \\
20\end{array}$ & $\begin{array}{l}17.70 \\
18.10\end{array}$ & -.40 & $\begin{array}{l}4.47 \\
2.55\end{array}$ & 38 & -.347 & .730 \\
\hline Bilgi yönetme & $\begin{array}{l}\text { Deney } \\
\text { Kontrol }\end{array}$ & $\begin{array}{l}20 \\
20\end{array}$ & $\begin{array}{l}32.70 \\
32.10\end{array}$ & .60 & $\begin{array}{l}6.14 \\
4.35\end{array}$ & 38 & .357 & .723 \\
\hline Toplam & $\begin{array}{l}\text { Deney } \\
\text { Kontrol }\end{array}$ & $\begin{array}{l}20 \\
20\end{array}$ & $\begin{array}{l}186.50 \\
185.80\end{array}$ & .70 & $\begin{array}{l}26.50 \\
20.23\end{array}$ & 38 & .94 & .926 \\
\hline
\end{tabular}

Not: ÜFE = Üstbilişsel Farkındalık Envanteri. 
Tablo 3 incelendiğinde, deney grubunun ön-test puan ortalaması $(\bar{X}=186.50)$, standart sapma değeri ( $S S$ $=26.50)$; kontrol grubunun ön-test puanlarının ortalaması $(\bar{X}=185.80)$, standart sapma değeri $(S S=20.23)$ olarak bulunmuştur. Gerek ölçekten alınan toplam puan gerekse ölçeğin alt boyutlarından alınan puanlar bakımından deney ve kontrol grubu arasında istatistiksel olarak anlamlı bir fark olmadığı görülmüştür $(p=.926 ; t=.94)$. Bu bulgular ışığında grupların çalışmaya uygun olduğuna karar verilerek uygulama sürecine başlanmıştır.

Uygulama tamamlandıktan sonra gruplar arasında üstbilişsel farkındalık düzeyleri açısından fark oluşup oluşmadığı belirleyebilmek amacıyla ÜFE son-test olarak her iki gruba da uygulanmıştır. Toplanan veriler ilişkisiz örneklemler t-testi ile analiz edilmiştir (Tablo 4).

Tablo 4

Deney ve Kontrol Grubunun ÜFE'den Aldılkları Son-test Puanları t-Testi Sonuçları

\begin{tabular}{|c|c|c|c|c|c|c|c|c|}
\hline Alt boyutlar & Grup & $n$ & $\bar{X}$ & Ortalamalar arası fark & $S S$ & $S D$ & $t$ & $p$ \\
\hline Açıklayıcı bilgi & $\begin{array}{c}\text { Deney } \\
\text { Kontrol }\end{array}$ & $\begin{array}{l}20 \\
20\end{array}$ & $\begin{array}{l}32.50 \\
29.70\end{array}$ & 2.80 & $\begin{array}{l}3.63 \\
3.68\end{array}$ & 38 & 2.419 & .020 \\
\hline İ̇slemsel bilgi & $\begin{array}{l}\text { Deney } \\
\text { Kontrol }\end{array}$ & $\begin{array}{l}20 \\
20\end{array}$ & $\begin{array}{l}14.75 \\
14.60\end{array}$ & 1.30 & $\begin{array}{l}2.73 \\
2.16\end{array}$ & 38 & 1.668 & .103 \\
\hline Durumsal bilgi & $\begin{array}{l}\text { Deney } \\
\text { Kontrol }\end{array}$ & $\begin{array}{l}20 \\
20\end{array}$ & $\begin{array}{l}19.80 \\
18.45\end{array}$ & 1.35 & $\begin{array}{l}3.18 \\
2.58\end{array}$ & 38 & 1.471 & .150 \\
\hline Planlama & $\begin{array}{l}\text { Deney } \\
\text { Kontrol }\end{array}$ & $\begin{array}{l}20 \\
20\end{array}$ & $\begin{array}{l}26.10 \\
23.95\end{array}$ & 2.15 & $\begin{array}{l}3.76 \\
4.27\end{array}$ & 38 & 1.688 & .100 \\
\hline İzleme & $\begin{array}{l}\text { Deney } \\
\text { Kontrol }\end{array}$ & $\begin{array}{l}20 \\
20\end{array}$ & $\begin{array}{l}27.85 \\
26.75\end{array}$ & 1.10 & $\begin{array}{l}4.73 \\
4.14\end{array}$ & 38 & .782 & .439 \\
\hline Değerlendirme & $\begin{array}{l}\text { Deney } \\
\text { Kontrol }\end{array}$ & $\begin{array}{l}20 \\
20\end{array}$ & $\begin{array}{l}22.50 \\
20.35\end{array}$ & 2.15 & $\begin{array}{l}3.36 \\
2.75\end{array}$ & 38 & 2.210 & .033 \\
\hline Hata ayıklama & $\begin{array}{l}\text { Deney } \\
\text { Kontrol }\end{array}$ & $\begin{array}{l}20 \\
20\end{array}$ & $\begin{array}{l}18.70 \\
17.35\end{array}$ & 1.35 & $\begin{array}{l}2.49 \\
3.24\end{array}$ & 38 & 1.474 & .149 \\
\hline Bilgi yönetme & $\begin{array}{l}\text { Deney } \\
\text { Kontrol }\end{array}$ & $\begin{array}{l}20 \\
20\end{array}$ & $\begin{array}{l}38.15 \\
32.05\end{array}$ & 6.10 & $\begin{array}{c}13.41 \\
4.76\end{array}$ & 38 & 1.916 & .063 \\
\hline Toplam & $\begin{array}{l}\text { Deney } \\
\text { Kontrol }\end{array}$ & $\begin{array}{l}20 \\
20 \\
\end{array}$ & $\begin{array}{l}200.35 \\
182.05 \\
\end{array}$ & 18.35 & $\begin{array}{l}28.06 \\
21.56 \\
\end{array}$ & 38 & 2.312 & .026 \\
\hline
\end{tabular}

Not: ÜFE = Üstbilişsel Farkındalık Envanteri.

Deney ve kontrol grubu öğrencilerinin ÜFE'den aldıkları son-test puanları incelendiğinde gruplar arasında anlamlı bir fark olduğu görülmüştür $(p=.026 ; t=2.312)$. Kontrol grubunda ölçekten alınan toplam puan ortalaması düşerken $(\bar{X}=182.05)$, deney grubunda $(\bar{X}=200.35)$ artış olduğu belirlenmiştir. Ölçeğin alt boyutları bakımından sonuçlar incelendiğinde ise açıklayıcı bilgi $(p=.020)$ ve değerlendirme $(p=.033)$ alt boyutlarında deney grubu lehine anlamlı fark olduğu belirlenmiştir.

\section{Anlatım Yöntemiyle Derslerin İşlendiği Kontrol Grubu Öğrencilerinin ÜFE'den Aldıkları Ön-test ve Son- test Puanlarının Karşılaş̧ırılması}

Araștırmanın ikinci sorusu anlatım yönteminin uygulandığı kontrol grubunun ön-test ve son-test puanları arasında üstbilişsel farkındalık düzeyi açısından anlamlı fark olup olmadığı belirlenmesidir. Bu amaçla kontrol grubundaki öğrencilerin ÜFE'den aldıkları ön-test ve son-test puanları ilişkili örneklemler t-testi kullanılarak karşılaştırılmış ve sonuçlar Tablo 5 'te verilmiştir. 
Tablo 5

Kontrol Grubu Öğrencilerinin ÜFE'den Aldıklarl Ön-test ve Son-test Puanlarının t-Testi Sonuçları

\begin{tabular}{lcccccc}
\hline \multicolumn{1}{c}{ Alt boyutlar } & $n$ & Ortalamalar arası fark & $S S$ & $S D$ & $t$ & $p$ \\
\hline Açılayıcı bilgi & 20 & -1.00 & 5.07 & 19 & -.881 & .390 \\
İşlemsel bilgi & 20 & 1.15 & 2.56 & 19 & 2.00 & .159 \\
Durumsal bilgi & 20 & .90 & 3.22 & 19 & 1.247 & .227 \\
Planlama & 20 & .90 & 5.65 & 19 & .712 & .485 \\
İzleme & 20 & .35 & 5.70 & 19 & .274 & .787 \\
Değerlendirme & 20 & .65 & 3.70 & 19 & .785 & .442 \\
Hata ayıklama & 20 & .75 & 3.20 & 19 & 1.045 & .309 \\
Bilgi yönetme & 20 & .05 & 5.32 & 19 & .042 & .967 \\
Toplam & 20 & 3.75 & 25.89 & 19 & .648 & .525 \\
\hline
\end{tabular}

Not: ÜFE = Üstbilișsel Farkındalık Envanteri.

Kontrol grubuna ait ön-test ve son-test ortalamaları incelendiğinde, uygulama sonrasında üstbilișsel farkındalık bakımından anlamlı bir farklılık oluşmadığı görülmüştür $(p=.525)$. Grubun verileri ÜFE'nin alt boyutlarına göre de incelenmiş ve açıklayıcı bilgi $(p=.390)$, işlemsel bilgi $(p=.159)$, durumsal bilgi $(p=.227)$, planlama $(p=.485)$, izleme $(p=.787)$, değerlendirme $(p=.442)$, hata ayıklama $(p=.309)$ ve bilgi yönetmede de $(p=.967)$ ön-test ortalamaları ile son-test ortalamaları arasında anlamlı bir fark oluşmadığı görülmüştür.

Üstbilişsel Farkındalığı Geliştirmek İçin Hazırlanan Etkinlikler ile Derslerin İşlendiği Deney Grubu Öğrencilerinin ÜFE'den Aldıkları Ön-test ve Son-test Puanlarının Karşılaştırılması

Araştırmanın üçüncü sorusu üstbilişsel farkındalığı geliştirmek için hazırlanan etkinliklerle derslerin işlendiği deney grubunda yer alan öğrencilerin ÜFE'den aldıkları ön-test ve son-test puanları arasında fark olup olmadığının belirlenmesidir. Bu amaçla deney grubundaki öğrencilerin ÜFE'den aldıkları ön-test ve son-test puanları ilişkili örneklemler t-testi kullanılarak karşılaştırılmıştır (Tablo 6).

Tablo 6

Deney Grubu Öğrencilerin ÜFE'den Aldıkları Ön-test ve Son-test Ortalama Puanlarının t-Testi Sonuçları

\begin{tabular}{llccccc}
\hline \multicolumn{1}{c}{ Alt boyutlar } & $n$ & Ortalamalar arası fark & $S S$ & $S D$ & $t$ & $p$ \\
\hline Açılkayıı bilgi & 20 & -1.75 & 4.66 & 19 & -1.67 & .110 \\
İşlemsel bilgi & 20 & -1.05 & 2.48 & 19 & -1.89 & .074 \\
Durumsal bilgi & 20 & -1.15 & 3.43 & 19 & -1.49 & .151 \\
Planlama & 20 & -2.25 & 4.35 & 19 & -2.31 & .032 \\
İzleme & 20 & -.150 & 5.44 & 19 & -.12 & .903 \\
Değerlendirme & 20 & -1.05 & 5.27 & 19 & -.89 & .385 \\
Hata Ayıklama & 20 & -1.00 & 5.01 & 19 & -.89 & .384 \\
Bilgi Yönetme & 20 & -5.45 & 14.31 & 19 & -1.70 & .105 \\
Toplam & 20 & -13.85 & 32.107 & 19 & -1.93 & .069 \\
\hline
\end{tabular}

Not: ÜFE $=$ Üstbilişsel Farkındalık Envanteri.

Uygulama tamamlandıktan sonra deney grubundan toplanan ön-test ve son-test puanlarına ilişkin sonuçlar incelendiğinde envanterden alınan toplam puan bakımından anlamlı bir fark oluşmadığı belirlenmiştir ( $p$ $=.069)$. Bu bulgudan hareketle deney grubunda yapılan uygulama sonrasında üstbilişsel farkındalık düzeyinde anlamlı bir değişim olmadığı görülmüsştür. Tablo 6'da görüldüğü gibi ölçeğin alt boyutlarında fark olup olmadığı incelendiğinde ise planlama alt boyutunda anlamlı düzeyde fark olduğu görülmüştür $(p=.032)$.

\section{Akademik Başarı Düzeylerinin Karşıllaştırılması}

Araştırmanın son sorusu üstbilişi geliştirmek için düzenlenen ders içeriklerinin uygulandığı deney grubu ile anlatım yönteminin uygulandığı kontrol grubu arasında akademik başarı düzeyleri açısından fark olup olmadığı sorusudur. Bu amaçla araştırmaya katılan grupların akademik başarılarının belirlenebilmesi için her iki gruba da akademik bilgi testi uygulanmış ve vize ve final notları ilişkisiz örneklemler t-testi kullanılarak analiz edilmiştir (Tablo 7). 
Tablo 7

Gruplar Arası Ders Başarı Düzeyi

\begin{tabular}{lccccccc}
\hline \multicolumn{1}{c}{ Grup } & $n$ & $\bar{X}$ & Ortalamalar aras1 fark & $S S$ & $S D$ & $t$ & $p$ \\
\hline Deney & 20 & 50.6 & \multirow{2}{*}{4.00} & 9.383 & \multirow{2}{*}{38} & \multirow{2}{*}{1.216} & .232 \\
Kontrol & 20 & 46.6 & & 11.334 & & \\
\hline
\end{tabular}

Deney grubunun test ortalaması 50.6; kontrol grubunun ortalaması 46.6 olarak bulunmuştur. Puanlar karşılaştırıldığında grupların akademik başarıları arasında anlamlı bir fark oluşmadığı görülmüştür $(p=.232 ; t=$ 1.216). Bu sonuçlara göre her iki grupta da bilginin edinimi benzer düzeylerde gerçekleşmiş ve bu da derse ilişkin akademik başarıda istatistiksel olarak anlamlı bir fark yaratmamıştır.

\section{Tartışma}

Öğretmen adaylarının üstbilişsel farkındalığını geliştirmek amacıyla yürütülen bu araştırmada, seçilen teorik bir dersin işlenmesi sırasında kullanılmak üzere öğretimsel etkinlikler düzenlenmiş, etkinlikler işlenecek konuya ve kazanımlara uygun şekilde ders içeriğine yerleştirilmiş ve üstbilişsel farkındalığın gelişimini ve öğrenmeyi destekleyen bir sınıf ortamı oluşturulmaya çalışılmıştır. Araştırmada Schraw ve Dennison (1994) tarafından geliştirilen ve Akın ve diğerleri (2007) tarafından Türkçe'ye uyarlanan Üstbilişsel Farkındalık Envanteri kullanılmıştır.

Araştırma bulguları üstbilişsel farkındalığı geliştirmek için düzenlenmiş olan etkinliklerle ders işlenmesinin ÜFE'den alınan toplam puan bakımından değerlendirildiğinde deney grubunda yer alan özel eğitim öğretmen adaylarının üstbilişsel farkındalık düzeyinin artmasını sağladığını, anlatım yöntemiyle derslerin işlendiği kontrol grubunda ise ölçekten alınan toplam puanda herhangi bir farklılık oluşmadığını göstermiştir. Bu bulgular alanyazındaki benzer çalışmalarla paralellik göstermektedir (Demiroğlu-Memiş, 2008; Duman, 2013; Gama, 2001; Volet, 1991; Y1ldız, 2012; Yokuş, 2013; Young \& Fry, 2008).

Deney ve kontrol grubu ölçeğin alt boyutlarından aldıkları puanlar birbiri ile karşılaştırıldığında ise açıklayıcı bilgi ve değerlendirme alt boyutlarında anlamlı fark olduğu belirlenmiştir. Açıklayıcı bilgide meydana gelen farklılığa deney grubunda bilgiyi geri çağırma ve ön bilgileri hatırlama etkinlikleri kullanılmasının neden olduğu düşünülmektedir. Her iki şekilde de mevcut bilgi aktif hale getirilmiş ve farkındalık sağlanması desteklenmiştir. Üstbilişsel bilgi, her zaman ifade edilmeye ihtiyaç duyan ya da beyan edilen bir bilgi değildir. Çocuklar bu bilgiyi ifade etmeden kendiliğinden kullanmakta ve göstermektedir (Karmiloff-Smith, 1992; Montgomery, 1992). Yetişkinler ise kendi uzman bilişlerini açık bir şekilde tanımlamakta ve kullanmakta büyük zorluklar yaşarlar (Bereiter \& Scardamalia, 1993). Belirtilen nedenlerle diğer bilgi türleri öğretmen adaylarına yeterince ve doğru olarak ifade edilememiş olabilir. Bu da bazı boyutlarda üstbilişsel bilgi ve farkındalıklarını artırmalarına rağmen, doğru bir şekilde kullanamadıklarını düşündürmektedir.

Yine gruplar arası karşılaştırmada değerlendirme alt boyutunda anlamlı düzeyde fark bulunması, etkinlikler aracılığıyla öğretimin etkililiğinin artırılması, derse katılımın öğrenmeye daha çok fayda sağladığı, dersteki stratejileri kendilerinin de denediği ve bu stratejileri geliştirdiğine işaret etmektedir. Alanyazında ders içeriğine yerleştirilmiş olan üstbilişsel stratejilerin ve bu stratejilerin kullanılması için sağlanan rehberliğin, öğrenme için amaç belirleme, planlama yapma, ek problemler belirleme, süreci gözden geçirme ve farkındalığa katkıları olduğu yönündeki araştırma bulguları bu sonuç ile paralellik göstermektedir (Vovides, 2005).

Araştırmanın alt sorularının cevaplanabilmesi için ölçeğin alt boyutlarındaki değişimi belirlemek amacıyla gruplar kendi içinde değerlendirildiğinde deney grubunda planlama boyutunda anlamlı düzeyde fark olduğu belirlenmiştir. Planlama becerisindeki bu artışa hâlihazırda sahip olunan stratejinin otomatik olarak kullanımı ve becerinin gerçekleştirilmesi için gerekenlere dair farkındalıkların desteklenmesinin neden olduğu düşünülebilir. Çünkü planlama, doğru stratejinin seçimini, performansı etkileyen süre, ortam gibi olanakların dağıtımını içerir (Schraw, 1998). Derste kullanılan etkinlikler açısından bakıldığında tablo, şematik düzenleyici, grafik, soru-cevap etkinlikleri gibi etkinlikler, öğrencilerin yabancı olmadıkları etkinliklerdir. Araştırma sırasında sözü geçen etkinlikler derslerde sıkça kullanılmıştır. Ancak sonuçlar öğretmen adaylarının hangi strateji, yöntem ya da tekniklerin hangi tür becerilerde nasıl kullanılabileceği konusunda her zaman yeterli deneyime sahip olmadıklarını düşündürmektedir. Ders başlangıcında önbilgilerin etkinleştirilmesi amacıyla sorulan sorular ve sonrasında yapılan dikkati çekme ve hedeften haberdar etme etkinliklerinde, öğrencilerin o dersteki öğrenme amacını fark etmeleri ve geliştirmeleri beklenen davranışlar arasındadır. İşlenişlerde sıkça kullanılan beyin fırtınası ve akran etkinliklerinin amaçları arasında ise soruna ilişkin çözüm yollarını tartışmak, düşünme becerilerini geliştirme yer almaktadır. Planlama alt boyutlarında belirlenen farkın nedenlerinin bunlar olduğu düşünülmektedir. 
Araştırmanın son sorusu olan akademik başarı boyutuna ilişkin bulgular incelendiğinde iki grup arasında ders başarısı açısından fark oluşmadığı görülmüştür. Bu sonucun olası nedenlerinden birinin başarıyı ölçme şekli olduğu düşünülebilir. Üstbiliş yapısı gereği süreç içerisinde gelişen ve farklı alanlara etkilerinin sürece bağlı olarak değerlendirilebileceği özelliklere sahiptir. Yaşla ve deneyimlerle birlikte gelişim düzeyi ve sergilenme şekli de değişebilmektedir. Araştırmada ise başarıyı ölçme şekli araştırmacı tarafindan geliştirilen çoktan seçmeli sorular kullanılarak yapılmıştır. Bu nedenle akademik başarıya etkisinin ölçülmesi noktasında ilerleyen araitırmalar için testler dışında gözlem, portfolyo, düşünme günlükleri gibi üstbilişin özelliklerine daha uygun ve birden çok ölçme değerlendirme yönteminin seçilmesi daha iyi bir tercih olabilir. Araştırma sırasında gözlemlenen durumlardan biri, öğrencilerin sınıfta yapılan etkinlikleri not almak, şema, grafik vb. örnekleri çizmek, not alırken yorumlayarak kendi ifadeleri ile betimlemek yerine fotoğrafını çekmeleridir. Üstbilişin özellikleri düşünüldüğünde bu tür davranışlar, öğretmen adaylarının farkındalıkları artsa dahi hazır olanı kullanma eğilimlerinin devam etmesi şeklinde yorumlanabilir. Bu noktada teknolojinin de süreci olumsuz etkilediği düşünülmektedir. Alanyazındaki araştırmalar incelendiğinde ise üstbilişsel strateji öğretimi ve kendini düzenlemeyle ders başarısı arasında pozitif ilişki tespit edilen bulgular olduğu gibi (Aktürk, 2010; Çalışkan, 2010; Jerkins, 2009; Park, 2000), aksi yönde bulgular da yer almaktadır (Aykut vd., 2016; Kimber, 2009; Sarıbaş, 2009).

Bütünsel bir bakış açısıyla değerlendirildiğinde, yapılan uygulamanın üstbilişsel farkındalıkta bir değişime neden olduğu, öğretmen adaylarının üstbilişsel farkındalıklarının düşük düzeyde olduğu ve müdahale edilmedikçe gelişiminde ve kazanılmasında sınırlılıklar bulunduğu görülmüştür. Öğretim süreci açısından bakıldığında üstbilişsel bilgi, beceri ve farkındalıkları desteklemek için alanyazında sıkça sesli düşünme protokollerine, kendini izleme stratejilerine ya da öğretilmesi planlanan konuya uygun bir stratejiye yer verildiği ve bu stratejilerin doğrudan öğretildiği göze çarpmaktadır. Bu araştırmada ise sözü geçen stratejiler işlenişlerin içine gömülü olarak kullanılmış, ayrıca bir strateji öğretimine yer verilmemiştir. Dolayısıyla uygulama süreci araştırmacı tarafından hazırlanan ve kullanılması tercih edilen öğretim etkinlikleri ile sınırlandırılmıştır. Her iki grupta da öğretim elemanı yetersizliği nedeniyle dersler araştırmacı tarafindan yürütülmüştür. Seçilmiş olan etkinliklerin, etkinlikler ile kazanımların eşleştirmesinde farklılaşmaya gidilmesinin ya da sürece yayılarak yapılan öğretim yerine farklı tercih ve düzenlemelerin etkililiğinin belirlenmesi için ise yeni araştırmalara ihtiyaç vardır.

Çalışmanın sonuçları üstbilişin gelişiminde kullanılan yaklaşımlar açısından da tartışılabilir. Kavramsallaştırılmasında çeşitli görüşler bulunan üstbiliş, bireyin gelişiminin birçok yönü ile ilgilenir (Lewis, 1998). Üstbilişin geliştirilmesine dönük çalışmalarda ya strateji öğretimine ya da destekleyici sosyal ortamlar oluşturmaya yönelik yaklaşımlar kullanıldığı görülmektedir. Uygulama alanında/sınıf ortamında hangisinin daha verimli olduğunu söylemek ise oldukça zordur. Bu konudaki tartışmaların odak noktası eğer sosyal çevre tarafından desteklenmiyorsa, bireylerin üstbilişsel yansıtma pratiği yapmasının zorlaşacak olmasıdır (Brown \& Campione, 1996; Lin, 2001). Okullarda üstbilişsel bilgi, beceri ve farkındalı̆̆ı destekleyici sosyal ortamların ve öğrenme kültürünün oluşturması öğretmenlerin sorumluluk alanlarındandır. Sözü edilen kültürün temel alındığ1 Çin'de ve Japonya'da öğrencilere öğrenim gördükleri süre boyunca üstbilişsel yansıtma, “otantik günlük alışkanlıklar" olarak kazandırılmaya çalışılmaktadır. Bilişsel alışkanlıkların değişebilmesi için üstbilişsel etkinlikler günlük öğretime, sabahları okulun beslenme rutinine, müzik vb. toplulukların günlük sürecine ve veli toplantılarına dahil edilmekte; ayrı veya izole edilmiş etkinlikler olarak değerlendirilmemektedir. Bu sayede öğrencilerde üstbilişsel gelişim sağlanabilmektedir. Bu nedenle bilişsel ve sosyal açıdan yetkin öğrenenlerin geliştirilmesinde üstbilişsel faaliyetleri merkeze alan dengeli bir sistem tasarımına vurgu yapılmaktadır (Lewis, 1998; Lin, 2001; Sato, 1997). Ancak kendisi bu tür becerilere sahip olmayan bir öğretmenin, sınıfında, öğrenme ve okul kültürü içinde üstbilişi destekleyici ortamlar oluşturulması beklenemez. Oysaki günümüz toplumunda gelişen teknoloji ile birlikte bilgiye erişim kolaylaşmış ve hızlanmıştır. Toplumun ise üstbilişsel becerilerini kullanarak doğru olan bilgiyi seçebilen, bilgiyi etkili kullanma ve geliştirme yoluyla kendi kendine öğrenebilen, yeniliklere uyum sağlayabilen, planlama yapabilen bireylere ihtiyacı vardır. Tüm bunlar üstbilişsel becerilerin kullanımını gerektirir. Erken yaşta gelişmeye başlayan üstbilişin desteklenmesinin ve ilerleyen yaşlarda kullanılabilmesinin ise yaşamın ve eğitimin tüm kademelerinde bu becerilerin gelişimine yardımcı ortamlar ve fırsatlar sağlanmasıyla mümkün olabileceği düşünülmektedir. $\mathrm{Bu}$ da üstbilişin öğretmen yetiştirme alanı ve yeterlikleri boyutundaki önemine dikkati çeker. Dolayısıyla öğretilen stratejilerin ve üstbilişin gelişimini destekleyici etkinliklerin günlük sosyal etkinliklerle bütünleştirilmesine ihtiyaç olduğu düşünülmektedir.

Hizmet öncesi dönemde öğretmen yetiştirilirken üstbilişsel etkinlikler tasarlanmasıyla oluşturulan destekleyici sosyal ortamlara strateji eğitimlerinin de eklenmesi ve kendi hakkında öğrenen olarak bireyin akademik ve sosyal yönlerinin de süreçte dikkate alınmasıyla müfredat oluşturulması, yaşanan sorunlara ve sınırlılıklara karşı bir çözüm oluşturabilir (Stein \& Markus, 1996). Böylelikle gerek program geliştirme alanındaki 
uzmanların gerekse sınıf içerisinde eğitim-öğretimden sorumlu olan öğretmenlerin her iki yaklaşım (destekleyici sosyal ortamlar ve strateji öğretimi) arasında dengeli bir ilişki kurabilmeleri için bazı önerilerde bulunmak mümkün olabilir. Öğrencilere bildikleri ve bilmedikleri konusunda kendilerini değerlendirmek için sık sık firsatlar sunarak ve kendi düşüncelerini ifade etmelerine yardımcı olarak, üstbilişsel etkinliklere dönük amaçların paylaşıldığı bir anlayışı teşvik ederek ve bireyin kültürel rolüne göre öğrenen olarak kendisi hakkındaki bilgisini geliştirmesine yardımcı olarak, destekleyici sosyal ortamlar ve strateji eğitimi arasında dinamik bir ilişki kurulabilir. Böylece sosyal bağlamda bir öğrenme kültürü oluşması sağlanabilir (Lin, 2001). Bu anlayışla yetişen öğretmen adayı ise gerek sınıfında gerekse toplumda üstbilişsel beceri, yeterlilik ve farkındalıkları artırmada etkili olabilir. Sözü edilen ilişkilerin kurulabilmesinin ise eğitim alanında çalışan uzman ve araştırmacıların koordineli olarak çalışması ile gerçekleştirilebileceği düşünülmektedir.

Yeni bakış açıları, öğretmenlerin öğretimsel karar vermelerini yönlendiren ve onlara pedagojik anlamda çabalarını ölçmeleri için mihenk taşı olarak nitelendirilebilecek becerilerin kazandırıldığı ideal uygulamaları işaret eder (Hammerness, 2006; Shulman \& Shulman, 2004). Mevcut programlarda öğretmen adayının kendisinden beklenen bu rolleri kazanıp kazanmadığı yeterince dikkate alınmamakta; yapılan revizyonlara rağmen Brown'un (1977) ifade ettiği şekilde öğretim elemanları alışkın oldukları ya da tercih ettikleri şekilde öğretim yapmakta ve derslerin belirlenen sürede, belirlenen başarı ile tamamlanmasının öğretmen yetiştirme için yeterli olduğu düşünmektedirler. Dolayısıyla öğretim elemanlarının alışkanlıklarından vazgeçerek öğrenme ve öğretme becerileri açısından kendi yeterliklerini sorgulaması; derslerde anlattıkları yöntem, teknik ve stratejileri öğretimler sırasında kendilerinin kullanması bunun için bir başlangıç olabilir. Lisans düzeyinde YÖK'ün (2011) ve mesleki yeterlilikler konusunda MEB' in (2017) yaptığı düzenlemelerde öz değerlendirme, öz düzenleme gibi beceriler birer gereklilik olarak belirtilmiş̧ir. Dolayısıyla tanımlamış olan yeterlilikleri karşılayacak düzenlemelerin işlevsel hale getirilmesine, öğretmen adaylarının seçimi ve atanması sırasında bu yeterliklerin karşılanmasına ilişkin alternatif değerlendirme yolları geliştirilmesine ihtiyaç vardır.

\section{Yazarların Katkı Düzeyleri}

İlk yazar tarafından alanyazın taraması yapıldıktan sonra araştırmanın konusuna, desenine, veri toplama aracına ve uygulanacağı gruba ortak karar verilmiştir. Araştırmada kullanılan ders başarı testi ilk yazar tarafindan hazırlanmıştır. Üstbilişsel Farkındalık Envanteri için ilk yazar tarafından ise envanteri Türkçe'ye uyarlayan araştırmacıdan izin alınmıştır. Uygulama sırasında ders içeriğinin düzenlenmesi, konu başlıklarının yazılması, kullanılacak etkinliklerin hazırlanması, işlenişlerin yazımı ilk araştırmacı tarafından yapılmıştır. İkinci yazardan düzenli olarak geri bildirimler alınmış ve düzeltmeler yapılmıştır. SPSS kullanılarak yapılan veri analizi için ölçme ve değerlendirme uzmanından yardım alınmıştır. Raporlama aşamasında ise ilk yazar ikinci yazardan geribildirimler alarak metni düzenlemiştir.

\section{Teşekkür}

Araştırmanın her aşamasında verdiği destekten dolayı danışmanım Prof. Dr. Çığıl Aykut'a teşekkür ederim. 


\section{Kaynaklar}

Akın, A., Abacı, R., \& Çetin, B. (2007). Bilişötesi Farkındalık Envanteri'nin Türkçe Formunun geçerlik ve güvenirlik çalışması [The validity and reliability of the Turkish Version of the Metacognitive Awareness Inventory]. Kuram ve Uygulamada Eğitim Bilimleri, 7(2), 658-680. https://toad.halileksi.net/sites/default/files/pdf/bilisotesi-farkindalik-envanteri-toad.pdf

Aktürk, A. O. (2010). Bilgisayar dersinde üstbiliş ögrretim stratejilerinin etkisi [Effect of metacognitive instructional strategies in computer course](Tez Numarası: 278534) [Doktora tezi, Selçuk Üniversitesi]. Yükseköğretim Kurulu Ulusal Tez Merkezi.

Artzt, A. F., \& Armour-Thomas, E. (1992). Development of a cognitive-metacognitive framework for protocol analysis of mathematical problem solving in small groups. Cognition and Instruction, 9(2), 137-175. https://doi.org/10.1207/s1532690xci0902_3

Aykut, Ç., Karasu, N., \& Kaplan, G. (2016). Özel eğitim öğretmen adaylarının üstbiliş farkındalıklarının tespiti [Determining metacognitive awareness of special education teacher candidates]. Ankara Üniversitesi Eğitim Bilimleri Fakültesi Özel Eğitim Dergisi, 17(3), 231-245. https://doi.org/10.21565/ozelegitimdergisi.267315

Baker, L., \& Brown, A. L. (1984). Metacognitive skills and reading. In P. D. Pearson, R. Barr, M. L. Kamil, \& P. Mosenthal (Eds.), Handbook of reading research (pp. 353-394). Longman.

Baştürk, M., \& Yücel, F. (2004). Eğitimde yeni yönelimler ve öğretmen adaylarının kaliteli eğitimden beklentileri. XII. Eğitim Bilimleri Kongresi Bildiriler: Cilt 1 [XII. Education Science's Congress Presentation: Vol. 1] içinde (ss. 515-527). Gazi Üniversitesi Eğitim Bilimleri Enstitüsü.

Bereiter, C., \& Scardamalia, M. (1993). Surpassing ourselves: An inquiry into the nature andimplications of expertise. Open Court. http://ikit.org/fulltext/1993surpassing/preface.pdf

Bielaczyc, K., Pirolli, P. L., \& Brown, A. L. (1995). Training in self-explanation and self-regulation strategies: Investigating the effects of knowledge acquisition activities on problem solving. Cognition and Instruction, 13(2), 221-252. https://doi.org/10.1207/s1532690xci1302_3

Brown, A. L. (1978). Knowing when, where, and how to remember: A problem of metacognition. In R. Glaser (Ed.), Advances in instructional psychology (pp. 6-59). Lawrence Erlbaum. http://eric.ed.gov/?id=ED146562

Brown, A. L. (1987). Metacognition, executive control, self-regulation, and other more mysterious mechanisms. In F. Weinert \& R. Kluwe (Eds.), Handbook of child psychology: Cognitive development (Vol. 3, pp. 263-340). Lawrence Erlbaum.

Brown, A. L. (1994). The advancement of learning. Educational Researcher, 23(8), 4-12. https://doi.org/10.3102/0013189X023008004

Brown, A. L., \& Campione, J. C. (1996). Psychological theory and the design of innovative learning environments: On procedures, principles, and systems. In R. Glaser (Ed.), Innovations in learning: New environments for education (pp. 289-325). Lawrence Erlbaum.

Creswell, J. W. (2009). Research design: Qualitative, quantitative, and mixed methods approaches. Sage Publications.

Çakır, B. (2011). Fen laboratuarı dersi kapsamında fen bilgisi öğretmen adaylarının üstbilis odakl ögrrenme ortaminda üstbilişlerinde değişim [Pre-service science teachers' metacognition in a science laboratory course with metacognitively oriented learning environment](Tez Numarası: 300615) [Yüksek lisans tezi, Ortadoğu Teknik Üniversitesi]. Yükseköğretim Kurulu Ulusal Tez Merkezi.

Çalışkan, M. (2010). Öğrenme stratejileri öğretiminin yürütücü biliş bilgisine, yürütücü biliş̧ becerilerini kullanmaya ve başarlya etkisi [The effects of learning strategies instruction on metacognitive knowledge, metacognitive skills and achievement] (Tez Numaras1: 264337) [Doktora tezi, Selçuk Üniversitesi]. Yükseköğretim Kurulu Ulusal Tez Merkezi. 
Demiroğlu-Memiş, A. (2018). Examination of legibility and writing speeds of primary school students with respect to writing disposition and writing style. Universal Journal od Educational Research, 6(5), 1050-1059. http://www.hrpub.org/download/20180430/UJER26-19511418.pdf

Duman, B. (2013). Üstbilișe dayalı bir öğretim uygulamasının öğretmen adaylarının akademik başarı, üstbilişsel farkındalık, başarı motivasyonu ve eleştirel düşünmelerine etkisi [The effect of an instructional practice based on metacognition upon teacher trainees academic achievement, metacognitive awareness, achievement motivation and critical thinking] (Tez Numarası: 333876) [Doktora tezi, Firat Üniversitesi]. Yükseköğretim Kurulu Ulusal Tez Merkezi.

Esendemir, Ö. (2011). Matematiksel problem çözme ve üstbiliş üzerine hazırlanan bir mesleki gelişim programı ve bu programin etkililiği [The effect of an practice based on metacognition upon teacher trainees academic achievement metacognitive awareness, eshievement motivation and critical thinking] (Tez Numarası: 280413) [Yüksek lisans tezi, Gaziantep Üniversitesi]. Yükseköğretim Kurulu Ulusal Tez Merkezi.

Flavell, J. H. (1976). Metacognitive aspects of problem solving. Metacognitive aspects of problem solving. In L. B. Resnick (Ed.), The nature of intelligence (pp. 231-235). Lawrence Erlbaum.

Flavell, J. H. (1979). Metacognition and cognitive monitoring-A new area of cognitive developmental inquiry. American Psychologist, 34(10), 906-911. https://doi.org/10.1037/0003-066X.34.10.906

Flavell, J. H., Miller, P., \& Miller, S. (2002). Cognitive development. Englewood Cliff.

Gallagher, S. A. (1997). Problem based learning: Where did it come from, what does it do, and where is it going. Journal of the Educaion of the Gifted, 20(4), 332-362. https://doi.org/10.1177/016235329702000402

Gama, C. (2001, June 19-23). The Role of metacognition in interactive learning environments. In G. Gauthier, C. Frasson, \& K. VanLehn (Eds.), 5th International Conference on Intelligent Tutoring Systems-Young Researchers' Track Proceedings (pp. https://citeseerx.ist.psu.edu/viewdoc/download?doi=10.1.1.18.2642\&rep=rep1\&type=pdf

Gama, C. (2005). Integrating metacognition instruction in interactive learning environments (Publication No: 413355) [Doctoral dissertation, University of Sussex]. ProQuest Dissertations and Theses Global.

Garner, R., \& Alexander, P. A. (1989). Metacognition: Answered and unanswered questions. Educational Psychologist, 24(2), 143-158, https://doi.org/10.1207/s15326985ep2402_2

Gönüllü, İ. (2010). Tip fakültesi ögrencilerinde ögrretimle yönlendirilmenin metabilişsel farkindalı̆g etkisi [The impact of metacognition training on metacognitive awarness of medical students] (Tez Numaras1: 279911) [Doktora tezi, Ankara Üniveritesi]. Yükseköğretim Kurulu Ulusal Tez Merkezi.

Hacker, D. J., Dunlosky, J., \& Graesser, A. C. (Eds.). (1998). The educational psychology series: Metacognition in educational theory and practice. Lawrence Erlbaum.

Hammerness, K. (2006). Seeing through teachers' eyes: Professional ideas and classroom practices. Teachers Collage Press.

Hartman, H., \& Stenberg, R. J. (1993). A broad BACEIS for improving thinking. Instructional Science, 21(5), 400-425. https://doi.org/10.1007/BF00121204

Hartman, H. J. (1998). Metacognition in teaching and learning; An introduction. Instructional Science, 26, 1-3, https://doi.org/10.1023/A:1003023628307

Hollingworth, R., \& McLoughlin, C. (2001). Developing science students' metacognitive problem solving skills online. Australian Jounral of Educational Technology, 17, 50-63. https://doi.org/10.14742/ajet.1772

House, A. W., House, B. G., \& Campbell, M. B. (1981). Measures of interobserver agreement: Calculation formula and distribution effect. Journal of Behavioral Assessment, 3, 37-57. https://doi.org/10.1007/BF01321350

Jacobs, J., \& Paris, S. (1987). Children's metacognition about reading. Issues in definition, measurement, and instruction. Educational Psychologist, 22, 255-278. https://doi.org/10.1080/00461520.1987.9653052 
Jenkins, J. (2009). English as a lingua franca: Interpretations and attitudes. World Englishes, 28(2), 200-207. https://doi.org/10.1111/j.1467-971X.2009.01582.x

Karasar, N. (2012). Bilimsel araştırma yöntemi [Scientific research method]. Nobel Yayıncılık.

Karmiloff-Smith, A. (1992). Learning, development, and conceptual change. Beyond modularity: A developmental perspective on cognitive science. Cambridge Press.

Kimber, C. T. (2009). The effect of training in self-regulated learning on math anxiety and achievement among preservice elementary teachers in a freshman course in mathematics concepts [Doctoral dissertation, Temple

University]. https://scholarshare.temple.edu/bitstream/handle/20.500.12613/1627/Kimber_temple_0225E_10044.pdf ?sequence $=1$

Lewis, C. C. (1998). Educating hearts and minds. Cambridge University Press.

Lin, X. (2001). Designing metacognitive activities. Educational Technology Research and Development, 49, 23 40. https://doi.org/10.1007/BF02504926

Lin, X. D., \& Lehman, J. (1999). Supporting learning of a computer-based biology environment: Effects of prompting college students to reflect on their own thinking. Journal of Research in Science Teaching, 36(7), 1-22. https://doi.org/10.1002/(SICI)1098-2736(199909)36:7\%3C837::AID-TEA6\%3E3.0.CO;2-U

Livingston, J. A. (1997). Metacognition: An overview. https://files.eric.ed.gov/fulltext/ED474273.pdf

Lucangeli, D., \& Cornoldi, C. (1997). Mathematics and metacognition: What is the nature of relationship. Mathematical Cognition, 3, 121-139. https://doi.org/10.1080/135467997387443

Marshall, M. (2003). Metacognition thinking about thinking is essential for learning. https://www.teachers.net/gazette/AUG00/marshall.html

Millı̂ Eğitim Bakanlığı [Ministry of National Education]. (2017). Öğretmen mesleği genel yeterlilikleri [General competencies for teaching profession]. https://oygm.meb.gov.tr/meb_iys_dosyalar/2017_12/11115355_YYRETMENLYK_MESLEYY_GENE L_YETERLYKLERY.pdf

Montgomery, D. E. (1992). Young children's theory of knowing: The development of a folk epistemology. Developmental Review, 12, 410-430. https://doi.org/10.1016/0273-2297(92)90016-U

Panaoura, A., \& Philippou, G. (2005). The measurement of young pupils' metacognitive ability in mathematics: The case of self-representation and self-evaluation. Proceedings of CERME, Vol. 4, 1-10. http://citeseerx.ist.psu.edu/viewdoc/download?doi=10.1.1.120.3575\&rep=rep1\&type=pdf.

Paris, S. G., Lipson, M. Y., \& Wixson, K. K. (1983). Becoming a strategic reader. Contemporary Educational Psychology, 8(3), 293-316. https://doi.org/10.1016/0361-476X(83)90018-8

Park, D. C. (2000). The basic mechanisms accounting for age-related decline in cognitive function. In D. C. Park \& N. Schwarz (Eds.), Cognitive aging: A primer (2nd ed., pp. 3-22). Psychology Press.

Pilten, P. (2008). Üstbiliş stratejileri öğretiminin ilköğretim beşinci sinıf öğrencilerinin matematiksel muhakeme becerilerine etkisi [The effect of metacognitive instruction on mathematical reasoning of fifth grade primary school students] (Tez Numarası: 214521) [Doktora tezi, Gazi Üniversitesi]. Yükseköğretim Kurulu Ulusal Tez Merkezi.

Pintrich, P. R. (2002). The role of metacognitive knowledge in learning, teaching, and assessing. Theory Into Practice, 41(4), 219-225. https://doi.org/10.1207/s15430421tip4104_3

Ridley, D. S., Schutz, P. A., Glanz, R. S., \& Weinstein, C. E. (1992). Self-regulated learning: The interactive influence of metacognitive awareness and goal-setting. Journal of Experimental Education, 60(4), 293306. https://doi.org/10.1080/00220973.1992.9943867

Santrock, J. W. (2001). Educational psychology. McGraw-Hill Company. 
Sarıbaş, D. (2009). Öz-düzenlemeye dayall öğrenme stratejilerini geliştirmeye yönelik laboratuar ortamının kavramsal anlama, bilimsel işlem becerisi ve kimyaya karşı tutum üzerindeki etkisi [Investigating the effect of laboratory environment aimed to improve self-regulated learning strategies on conceptual understanding, science process skills and attitude towards chemistry] (Tez Numaras1: 420677) [Doktora tezi, Marmara Üniversitesi]. Yükseköğretim Kurulu Ulusal Tez Merkezi.

Sato, N. E. (1997, March 24-28). Forms and functions of reflection in Japanese elementary schools [Paper presentation]. American Educational Research Association Meeting, Chicago, USA.

Scheidler, K. P. (1994). Changing teacher thinking in school restructuring: A view from the trenches. Journal of Education, 176(2), 45-56. https://doi.org/10.1177\%2F002205749417600207

Schnider, W. (1998). Performance prediction in young children: Effects of skills, metacognition an wishful thinking. Developmental Science, 1(2), 291-297. https://psycnet.apa.org/doi/10.1111/1467-7687.00044

Schoenfeld, A. H. (1987). What's all the fuss about metacognition? In A. H. Schoenfeld (Ed.), Cognitive science and mathematics education (pp. 189-215). Lawrence Erlbaum.

Schraw, G. (1998). Promoting general metacognitive awareness. Instructional Science, 26(1-2), 113-125. https://www.researchgate.net/publication/227166212 Promoting_General_Metacognitive_Awareness

Schraw, G., \& Dennison, R. S. (1994) Assessing metacognitive awareness. Contemporary Educational Psychology 19, 460-475. https://doi.org/10.1006/ceps.1994.1033

Schraw, G., \& Moshman, D. (1995). Metacognitive theories. Educational Psychology Review, 7, 351-371. https://www.jstor.org/stable/23359367?seq=1\#metadata_info_tab_contents

Sezgin-Memnun, D., \& Akkaya, R. (2012). An investigation of pre-service primary school mathematics, science and classroom teachers' metacognitive awareness in terms of knowledge of and regulation of cognition. Kuramsal Eğitimbilim Dergisi, 5(3), 312-329. https://www.pegem.net/dosyalar/dokuman/13906220140131153750-4.pdf

Shulman, L. S., \& Shulman, J. H. (2004). How and what teachers learn: A shifting perspective. Journal of Curriculum Studies, 36(2), 257-271. https://doi.org/10.1080/0022027032000148298

Simons, P. R. J. (1996). Metacognition. In E. De Corte \& F. E. Weinert (Eds.), International encyclopedia of developmental and instructional psychology (pp. 436-444). Elsevier Science.

Sontag, E., Purke, P. J., \& York, R. (1973). Considerations for serving the severely handicapped in the public schools. Education and Training of the Mentally Retarded, 8, 20-26. https://www.jstor.org/stable/pdf/23876322.pdf?refreqid=excelsior\%3Aa663065da017f477c85c0f092f26 $\underline{993 \mathrm{f}}$

Spillane, J. S., \& Jennings, N. E. (1997). Aligned instructional policy and ambitious pedagogy: Exploring instructional reform from the classroom perspective. Teachers College Record, 98(3), 449-481. https://www.scopus.com/record/display.uri?eid=2-s2.0-0031482940\&origin=resultslist\&sort=plff\&cite $=2-\mathrm{s} 2.0-$ $0031482940 \&$ src $=$ s $\&$ imp $=t \&$ sid $=0 \mathrm{fb} 11140 \mathrm{dac} 9 \mathrm{bcbd6b} 8 \mathrm{~b} 90 \mathrm{e} 803 \mathrm{f} 0791 \mathrm{c} \&$ sot $=\mathrm{cite} \& \mathrm{sdt}=\mathrm{a} \& \mathrm{sl}=0$

Stein, K. F., \& Markus, H. R. (1996). The role of the self in behavior change. Journal of Psychotherapy Integration, 6(4), 349-384. https://psycnet.apa.org/doi/10.1037/h0101118

Şencan, H. (2005). Sosyal ve davranışsal ölçümlerde güvenilirlik ve geçerlilik [Reliability and validity in social and behavioral measures]. Seçkin Yayınc1lık.

Volet, S. E. (1991). Modelling and coaching of relevant metacognitive strategies for enhancing university student learning. Learning and Instruction, 1, 319-336. https://doi.org/10.1016/0959-4752(91)90012-W

Vovides, Y. (2005). Investigating learning from hypermedia via the implementation of a computer-based metacognition training regimen and a hypermedia program (Publication No: 3172455) [Doctoral dissertation, University of Iowa]. ProQuest Dissertations and Theses Global. 
Wilson, J. (2001). Methodological difficulties of assessing metacognition: A new approach [Paper presentation]. Annual Meeting of the Australian Association for Research in Education Fremantle, Western Australia. https://files.eric.ed.gov/fulltext/ED460143.pdf

Yangın, S. (2014). Üstbiliş stratejisine dayalı biyoloji öğretiminin sınıf öğretmeni adaylarının başarıları ve tutumları üzerindeki etkisi [The effect of metaconceptual teaching activities on pre-service science teachers' metacognitive awareness, motivation towards learning biology and academic achievement]. Education Sciences, 9(1), 1-18. https://dergipark.org.tr/tr/download/article-file/185376

Yıldırım, A., \& Şimşek, H. (2005). Sosyal bilimlerde nitel araştırma yöntemleri [Qualitative research methods in the social sciences] (5. baskı). Seçkin Yayınevi.

Yıldız, İ. (2012). Web tabanlı akran değerlendirme sistemine yerleştirilmiş yönlendirici yardım stratejilerinin hizmet öncesi ögrretmenlerin yansitıcı düsünme ve ögretmen öz-yeterlilikleri üzerindeki etkisi [Effects of scaffolding strategies embedded within webbased peer evaluation system on pre-service teachers' reflective thinking and self-efficacy] (Tez Numarasi: 420677) [Doktora tezi, Orta Doğu Teknik Üniversitesi]. Yükseköğretim Kurulu Ulusal Tez Merkezi.

Yokuş, T. (2013). Üstbilişin gitar performans başarısına etkisi [Impact of metacognition on guitar performance achievement]. Marmara Üniversitesi Atatürk Eğitim Fakültesi Eğitim Bilimleri Dergisi, 31, 161-175. https://dergipark.org.tr/tr/pub/maruaebd/issue/354/1919

Young, A., \& Fry, J. D. (2008). Metacognitive awareness and academic achievement in college students. Journal of the Scholarship of Teaching and Learning, 8(2), 1-10. https://www.researchgate.net/publication/228345722_Metacognitive_Awareness_and_Academic_Achie vement in College_Students/fulltext/000078540cf23f86393ce958/Metacognitive-Awareness-andAcademic-Achievement-in-College-Students.pdf

Yükseköğretim Kurulu [Council of Higher Education]. (2011). Türkiye yükseköğretim yeterlilikler çerçevesi (TYYÇ) temel alan yeterlilikleri ögretmen yetiştirme ve ĕgitim bilimleri [National Qualifications Framework for Higher Education in Turkey]. https://epdad.org.tr/data/genel/pdf/Genel-8.pdf

Yükseköğretim Kurulu [Council of Higher Education]. (2016). Özel eğitim öğretmenliği lisans programı [Special education teaching undergraduate program]. https://www.yok.gov.tr/Documents/Kurumsal/egitim_ogretim_dairesi/Yeni-Ogretmen-YetistirmeLisans-Programlari/Ozel_Egitim_Ogretmenligi_Lisans_Programi.pdf 


\section{Ankara University Faculty of Educational Sciences Journal of Special Education}

2022, 23(1), 23-51
RESEARCH

Recieved Date: 08.04.20

Accepted Date: 12.03.21

OnlineFirst: 11.04 .21

\title{
The Effect of Teaching Activities Organized to Improve Metacognition Upon Teacher Candidates' Metacognitive Awareness*
}

\author{
Gamze Kaplan $(D 1$
}

\author{
Çı̆̆ıl Aykut ${ }^{(i D} 2$
}

\begin{abstract}
Introduction: The aim of this study is to investigate the effects of metacognitive learning activities presented in the lesson on the development of metacognitive awareness of teacher candidates. The study was conducted in the course of Integration in Special Education in the second year curriculum of the Department of Special Education.

Method: A quasi-experimental method was conducted in the research. The pre-test post-test control group design was utilized. The students were assigned to two categories: The experimental group $(n=20)$ and the control group $(n=20)$. Groups were randomly divided into two categories. Data were collected using Metacognitive Awareness Inventory.

Findings: When the experimental group and the control group were compared, no significant difference was found between metacognitive awareness in terms of total score obtained from the scale. While there was a significant difference in the planning from the sub-dimensions of the scale in favor of the experimental group, there was no significant difference in the other sub-dimensions. When the groups were compared with each other, there was a difference between the total score. There was also a difference between the declarative knowledge and evaluation sub-dimensions in favor of the experimental group.
\end{abstract}

Discussion: The study revealed that the metacognitive learning activities resulted in a change in metacognitive awareness. It also showed that the teacher candidates' metacognitive awareness was low. There were limitations in their development and acquisition prior to the implementation.

Keywords: Metacognition, metacognitive awareness, special education, teacher trainig, higher education.

To cite: Kaplan, G., \& Aykut, Ç. (2022). The effect of teaching activities organized to improve metacognition upon teacher candidates' metacognitive awareness. Ankara University Faculty of Educational Sciences Journal of Special Education, 23(1), 23-51. https://doi.org/10.21565/ozelegitimdergisi.715775

\footnotetext{
*This study is based on the doctoral dissertation of the first writer. The dissertation was supervised by the second author. ${ }^{1}$ Corresponding Author: Res. Asisst. Dr., Bülent Ecevit University, E-mail: kplngamze @ gmail.com, https://orcid.org/00000002-3853-322X

2Prof., Gazi University, E-mail: cigil@gazi.edu.tr, https://orcid.org/0000-0002-0365-9930
} 


\section{Introduction}

Metacognition was named for the first time by Flavell (1976). The cognitive processes of the individual and the conscious structuring of this process were defined as finding and organizing the necessary information among the stored information. Different names have been used by different researchers such as thinking about thinking, cognition about cognition (Brown, 1987; Garner \& Alexander, 1989; Jacops \& Paris, 1987).

As in the definition of metacognition, there are different opinions about its components. Flavell (1979) mentioned two components: metacognitive knowledge and metacognitive experiences. In different studies the components of metacognition are mentioned through metacognitive knowledge and regulation of metacognition (Hollingworth \& McLoughlin, 2001; Schraw \& Moshman, 1995); monitoring, self-regulation and metacognitive information (Flavell et al., 2002); metacognitive knowledge, regulation of cognition and metacognitive belief (Lucangeli \& Cornoldi, 1997; Schoenfeld, 1987; Simons, 1996). Although there is a variety of expressions about the components of metacognition, knowledge of cognition and regulation of cognition are the main components (Brown, 1987; Pintrich, 2002; Schraw \& Dennison,1994; Schraw \& Moshman, 1995). Metacognitive knowledge refers to the individual's knowledge of his or her own cognitive activities or general knowledge and beliefs about cognition (Flavell, 1979; Schraw, 1998). Metacognitive information includes declarative, procedural and conditional knowledge (Brown, 1987; Jacobs \& Paris, 1987). The regulation of cognition is that the individual consciously selects, uses and manages thinking strategies in the problem solving process (Santrock, 2001). The regulation of cognition consists of sub-skills such as planning, managing information, monitoring, error correction and evaluation (Artzt \& Armor-Thomas, 1992; Schraw, 1998; Schraw \& Dennison, 1994).

Metacognition is a developmental process. It is possible to develop metacognitive knowledge, skills, and the use of metacognitive skills can be taught (Brown, 1987; Gardner \& Alexander, 1989; Schnider, 1998). Another concept related to metacognition is metacognitive awareness. Metacognitive awareness is the use of thinking skills to develop awareness about the sub-components of metacognitive knowledge (individual, strategy and skill) in a given situation as defined in different ways, such as being aware of one's own thoughts (Ridley et al., 1992).

In the studies conducted to develop metacognitive awareness, it is seen that two approaches have been adopted: direct teaching of metacognitive strategies and creating environmental regulations and social environments that support metacognitive and metacognitive awareness (Hartman, 1998; Lin, 2001). There are four ways that metacognitive awareness can be developed in the classroom environment (Hartman, 1998; Hartman \& Sternberg, 1993; Schraw, 1998;): Increasing general awareness of the importance of the metacognition, improving cognitive knowledge, developing skills related to the regulation of cognition, setting the environment in a way that supports metacognitive awareness.

In approaches to organizing the environment to increase metacognitive awareness, it is aimed to provide students with an environment where metacognitive awareness is valued and they are encouraged to use metacognitive skills. They are expected to adopt the reflective habit at the end of the process (Lin, 2001; Lin \& Lehman, 1999). The important point is to be able to design effective metacognitive activities and to adopt a systematic approach in the use of metacognitive strategies.

If the person is aware of his/her learning style and can transfer this awareness to academic and daily life, it may be possible to increase achievement. Therefore, using the regulations aimed at improving the metacognition and also applied in the field of teacher training is important (Scheidler, 1994; Spillane \& Jennings, 1997). In this context, when teacher training and metacognition are evaluated together, it is noted that teachers have two main roles related to metacognition. The first of these roles is promoting the students' metacognitive knowledge and skills; the second is utilizing metacognitive activities in teaching, curriculum and evaluation (Hartman \& Stenberg, 1993). The development of metacognitive awareness of teacher candidates may be possible by including activities that develop metacognitive knowledge, skills and awareness in the courses they take during teacher education, and by organizing the course content to support metacognitive development (Sezgin et al., 2012).

In this study, an instuctional plan was designed based on the regulation of the environment to improve metacognitive awareness, thinking that it would serve to support metacognitive thinking skills of teacher candidates both in a personal and professional sense. The aim of this study was to examine the effects of metacognitive teaching activities used by the lecturer in the presentation of the course on the development of metacognitive awareness of teacher candidates. The main question and sub-questions of the research were:

1. Do teaching activities organized to improve metacognitive awareness have an impact on teacher candidates' metacognitive awareness? 
1.1. Is there a significant difference in terms of metacognitive awareness between the pre-test and posttest scores of the experimental group using teaching activities arranged to improve metacognitive awareness and the control group using the expository method?

1.2. Is there a significant difference in terms of metacognitive awareness between the pre-test and posttest scores of the control group using the expository method?

1.3. Is there a significant difference in terms of metacognitive awareness between the pre-test and posttest scores of the experimental group using teaching activities arranged to improve metacognitive awareness?

2. Is there a significant difference in academic achievement levels between the experimental group using teaching activities that are arranged to develop metacognitive awareness, and the control group using the expository method?

\section{Method}

Quasi-experimental control group pre-test-post-test design was used in the study. In the quasiexperimental design, control and experimental groups are chosen by criteria, not by chance. The researcher determines one of the available groups as the experimental and the other as the control group (Karasar, 2012). The dependent variables of the study are students' awareness levels and course success. The independent variable is the teaching activities offered to improve metacognitive awareness.

\section{Sampling}

In selecting the study group, convenience sampling was utilized. Convenience sampling provides speed and practicality to the researcher. In this sampling method, the researcher chooses a situation that is nearby and easy to access (Yıldırım \& Şimşek, 2006). In this study, because of the availability of the teacher candidates, participants were identified through easy accessibility in the targeted sample.

Permission was obtained from the Human Research Ethics Committee of Zonguldak Bülent Ecevit University to conduct the study (30.11.2017, protocol no: 271). The study was carried out with the students attending the $2^{\text {nd }}$ year of Special Education Department at Faculty of Education, Zonguldak Bülent Ecevit University. The group was divided into two groups as experimental group $(n=20)$ and control group $(n=20)$. The groups were determined by randomly.

\section{Data Collection}

Data were collected with the Metacognitive Awareness Inventory (MAI) developed by Schraw and Dennison (1994) and Lesson Success Test developed by the researcher.

\section{Metacognitive Awareness Inventory (MAI)}

MAI is a self-report inventory and used for metacognitive awareness levels among adult population. It includes 52-items. Each item is rated on 5-point Likert-type scale (1-always false to 5-always true). High scores indicate strong agreement. The lowest score that can be obtained from the inventory is 52 , and the highest score is 260.

\section{Success Test}

It was developed by the researcher to be used for evaluating learning achievement. While writing the questions, the outcomes of the course were taken into consideration. 50 questions were created for the mid-term exam and 60 questions for the final exam. Expert opinion was received for the questions. The cognitive taxonomy and difficulty levels of the questions were checked. The questions were divided into three groups as easy, medium, and hard. They were placed in the pre-test-post-test with a distribution of $20 \%, 60 \%$, and $20 \%$.

\section{Experimental Process}

The research consisted of three phases. During the preparation phase, the course and the group in which the application would be made were determined, the measurement tools were selected and the content of the course was developed. In the application phase, which was the second phase, the collection of pre-test data and the implementation were included. After the application, which was the last phase, the final test data was collected (Figure 1). In the application phase, which was the second phase, the collection of pre-test data and the 
implementation were included. After the application, which was the last phase, the final test data were collected (Figure 1).

\section{Figure 1}

Stages of Research

- Editing the lesson's content
- Preparation of measurement instruments
- Preparations for the working group

Note: MAI = Metacognitive Awarness Inventory.

\section{Development of The Course Content}

The development of the course content, which was in the first part of the preparatory stage, consisted of two stages: the writing of the topics and learning outcomes and the selection of learning-teaching activities. The process of writing the learning outcomes was summarized below and shown in Figure 2.

\section{Figure 2}

Writing of Topics and Achievement

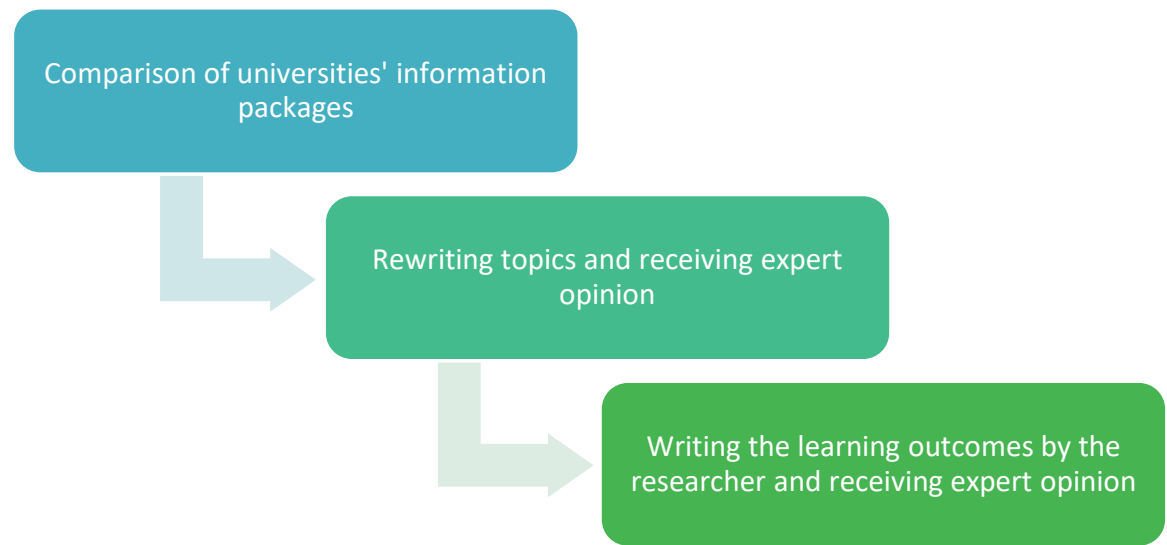

Writing of Topics and Learning Outcomes. To determine the course content and learning outcomes, information packages of universities including special education teaching programs were first reached. Common and different points were detected by comparing the information packages. When the learning outcomes were examined, most of them did not have the characteristics that should be found in the learning outcomes, these did not match with the course content and they were written incomplete. With the help of the literature and the reference books used by the researchers in the course, the topics were rewritten and the opinion of expert was taken. After determining the topic titles, the appropriate learning outcomes were written in these titles and lined up taxonomically. It was distributed over weeks according to the characteristics, content and time needed for the 
delivering of the subject and sent back to expert opinion again. After the necessary corrections were made, the topics and learning outcomes were finalized.

Choosing of Learning and Teaching Activities. Instead of teaching a specific strategy, it was planned to improve metacognitive awareness while subject knowledge was provided in the daily routine of the course through activities embedded in the content of the lesson. The steps that were followed during the selection of the events and the writing of the plans were shown in Figure 3.

\section{Figure 3}

The Selection of Activities and Writing of the Daily Plans

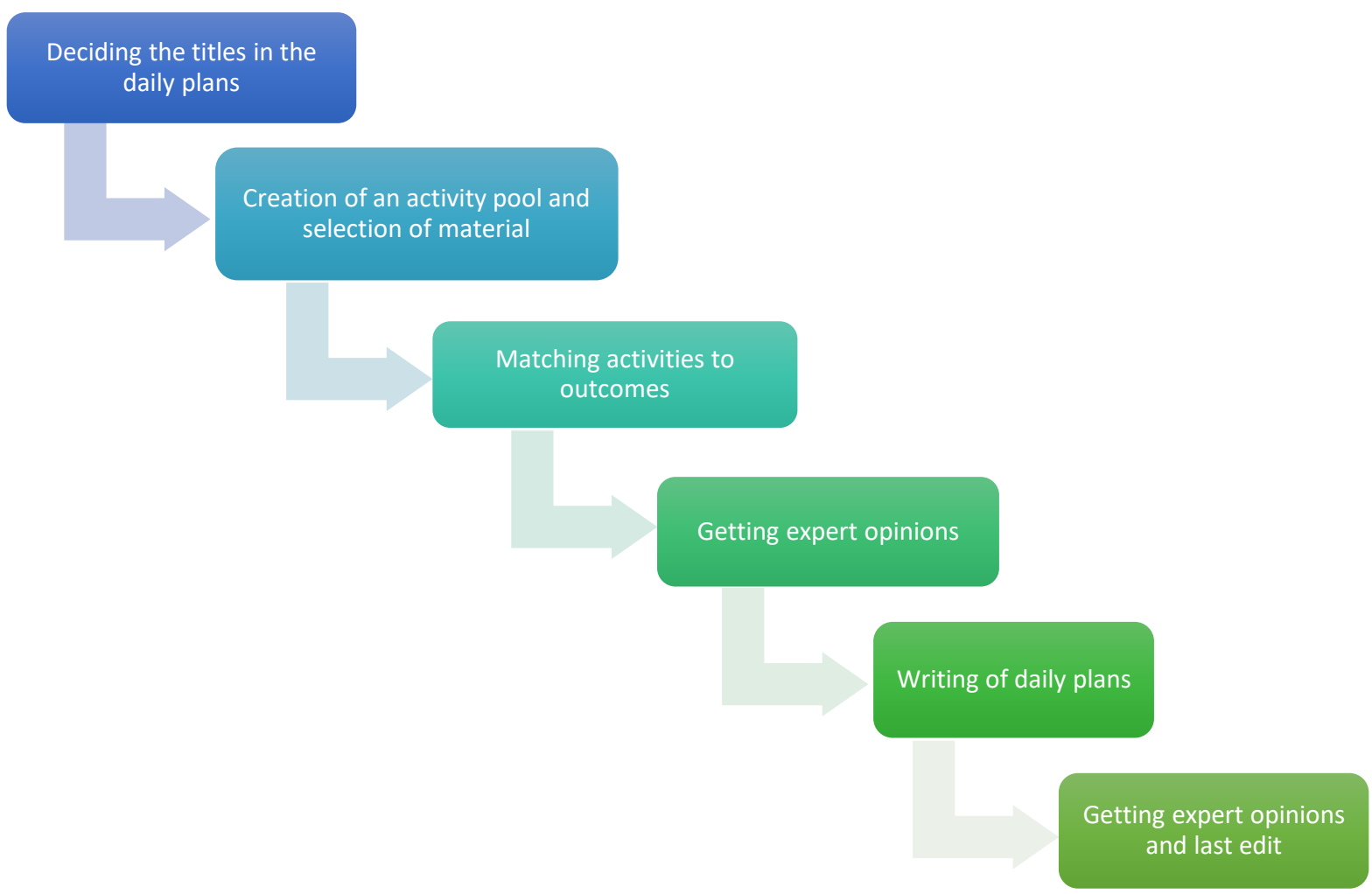

Before writing the daily plans, expert opinion was received on the sections included in each of the plans. The introduction part of each daily plans included some information such as the name of the unit, the name of the subject, the learning outcomes planned to be acquired within this course, teaching methods, techniques and strategies, materials, activities to attract attention and inform the goal. Review and evaluation activities were included in the last part.

In the following, the determination process of learning-teaching activities appropriate to the learning outcomes began. A pool of activities was created by reviewing the literature. Daily plans were prepared for 11 weeks and the appropriate one was selected for each learning outcome. The distribution of the activities according to the skills was shown in the Figure 4. After the activities were selected, the materials were identified. Teaching materials such as worksheets, pictures, videos, presentations, graphics, schematic organizers, chart templates, case studies and various written materials were prepared.

Learning outcomes that were prepared in previous stages and distributed over weeks were combined with the activities. In the following, daily plans started to be written. The plans were sent to three experts for evaluation. After their feedback, the researcher also communicated with the Curriculum and Instruction Department Specialist and reorganized the processes, activities and materials. After these rearrangements, with another expert, who is experienced in metacognition studies, the naming and use of activities were studied again. All views and studies were prepared and finalized for implementation. 


\section{Figure 4}

\section{Distribution of Activities}

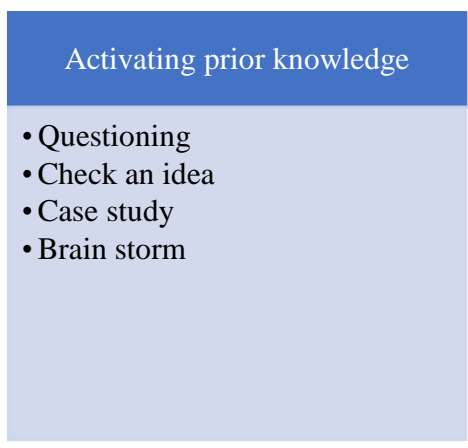

Calling, structuring and building relationship about information

- Paraphrase

- Mnemonics

- Content configuration

- Grouping

- Organization

- Tagging activity

- Summarizing

- İnference skill
Monitoring, evaluation and planning activities

- Metacognitive questions

- Brain storming

- Think aloud

- Discussion

- Peer assesment

- Self monitoring strategy

- Small group activities

After all these procedures mentioned in the preperation phase were completed, the implementation phase of the study was passed and preliminary data were collected with MAI. In the final phase of the study MAI was administered as the final test in both groups. Final exams were conducted using the second course success test. The data was analyzed. The post-implementation phase was completed.

\section{Treatment Fidelity}

Treatment fidelity was calculated to determine whether the independent variable was applied as planned in the study. In order to calculate the treatment fidelity, all courses were video recorded. A form was developed to evaluate the instruction. $30 \%$ of the video recordings were randomly selected and evaluated by a field expert who gained the doctoral degree, in addition to the researcher. A likert-type scale developed by the researcher was used in the assessment. During the calculation, "the correct behavior observed in the practice/the correct behavior that should be observed x100" formula was used. The treatment fidelity of the study, as can be seen in the Table 1, was calculated as $94 \%$. This value was e high as endorsed by House et al. (1981).

\section{Table 1}

Treatment Fidelity

\begin{tabular}{llc}
\hline \multicolumn{1}{c}{ Weeks } & \multicolumn{1}{c}{ Content } & Treatment fidelity (\%) \\
\hline 3.Week & Children with special needs and inclusion & 91 \\
4.Week & Assesment and IEP & 96 \\
7.Week & Instructional adaptations & 93 \\
9.Week & Behavior Management & 95 \\
Mean & & 93.75 \\
\hline
\end{tabular}

\section{Results}

The aim of this study was to examine the effects of metacognitive teaching activities on the development of metacognitive awareness of teacher candidates. This section includes the findings obtained by analyzing the data collected in accordance with the aim of the study.

\section{Comparison of the Experimental and Control Group Pre-test and Post-test Mean Scores Received from the MAI}

The first question of the study was to determine whether there was a significant difference in terms of metacognitive awareness between the experimental group, where the content of the course was organized to improve metacognitive awareness, and the control group where the expository instruction method was applied. At the beginning of the study, in order to determine the equivalence of the groups, the pre-test data collected from the experimental and control groups were compared with the independent samples by t-test, and the results were given in Table 2. 
Table 2

Comparison of Experimental and Control Group Pre-test Data

\begin{tabular}{|c|c|c|c|c|c|c|c|c|}
\hline Sub-dimensions & Group & $n$ & $\bar{X}$ & Mean difference & $S D$ & $d f$ & $t$ & $p$ \\
\hline $\begin{array}{c}\text { Declarative } \\
\text { knowledge }\end{array}$ & $\begin{array}{l}\text { Experimental } \\
\text { Control }\end{array}$ & $\begin{array}{l}20 \\
20\end{array}$ & $\begin{array}{l}30.75 \\
28.70\end{array}$ & 2.05 & $\begin{array}{l}3.41 \\
4.95\end{array}$ & 38 & 1.524 & .136 \\
\hline $\begin{array}{l}\text { Procedural } \\
\text { knowledge }\end{array}$ & $\begin{array}{l}\text { Experimental } \\
\text { Control }\end{array}$ & $\begin{array}{l}20 \\
20\end{array}$ & $\begin{array}{l}13.70 \\
14.60\end{array}$ & -.90 & $\begin{array}{l}2.57 \\
1.70\end{array}$ & 38 & $1 . \overline{304}$ & .200 \\
\hline $\begin{array}{r}\text { Conditional } \\
\text { knowledge }\end{array}$ & $\begin{array}{l}\text { Experimental } \\
\text { Control }\end{array}$ & $\begin{array}{l}20 \\
20\end{array}$ & $\begin{array}{l}18.65 \\
19.35\end{array}$ & -.70 & $\begin{array}{l}2.88 \\
2.68\end{array}$ & 38 & -.794 & .432 \\
\hline Planing & $\begin{array}{l}\text { Experimental } \\
\text { Control }\end{array}$ & $\begin{array}{l}20 \\
20\end{array}$ & $\begin{array}{l}23.85 \\
24.85\end{array}$ & -1.00 & $\begin{array}{l}4.52 \\
2.77\end{array}$ & 38 & -.843 & .405 \\
\hline Monitoring & $\begin{array}{l}\text { Experimental } \\
\text { Control }\end{array}$ & $\begin{array}{l}20 \\
20\end{array}$ & $\begin{array}{l}27.70 \\
27.10\end{array}$ & .60 & $\begin{array}{l}5.19 \\
4.20\end{array}$ & 38 & .402 & .690 \\
\hline Evaluation & $\begin{array}{l}\text { Experimental } \\
\text { Control }\end{array}$ & $\begin{array}{l}20 \\
20\end{array}$ & $\begin{array}{l}21.45 \\
21.00\end{array}$ & .45 & $\begin{array}{l}3.83 \\
2.86\end{array}$ & 38 & .421 & .676 \\
\hline Debugging & $\begin{array}{l}\text { Experimental } \\
\text { Control }\end{array}$ & $\begin{array}{l}20 \\
20\end{array}$ & $\begin{array}{l}17.70 \\
18.10\end{array}$ & -.40 & $\begin{array}{l}4.47 \\
2.55\end{array}$ & 38 & -.347 & .730 \\
\hline $\begin{array}{l}\text { Information } \\
\text { management }\end{array}$ & $\begin{array}{l}\text { Experimental } \\
\text { Control }\end{array}$ & $\begin{array}{l}20 \\
20\end{array}$ & $\begin{array}{l}32.70 \\
32.10\end{array}$ & .60 & $\begin{array}{l}6.14 \\
4.35\end{array}$ & 38 & .357 & .723 \\
\hline Total & $\begin{array}{l}\text { Experimental } \\
\text { Control }\end{array}$ & $\begin{array}{l}20 \\
20\end{array}$ & $\begin{array}{l}186.50 \\
185.80\end{array}$ & .70 & $\begin{array}{l}26.50 \\
20.23\end{array}$ & 38 & .94 & .926 \\
\hline
\end{tabular}

Analysis showed that there was no statistically significant difference between the groups in terms of both the total score obtained from the scale and the scores obtained from the sub dimensions of the scale $(p=.926)$. Thus, it was decided that the groups were suitable for the study and the implementation process started.

After the experimental process, independent samples were t-tested to determine whether there was a difference between the groups. The results were given in Table 3.

Table 3

Comparison of Experimental and Control Group Post-test Data

\begin{tabular}{|c|c|c|c|c|c|c|c|c|}
\hline Sub-dimensions & Group & $n$ & $\bar{X}$ & Mean difference & $S D$ & $d f$ & $t$ & $p$ \\
\hline $\begin{array}{l}\text { Declarative } \\
\text { knowledge }\end{array}$ & $\begin{array}{l}\text { Experimental } \\
\text { Control }\end{array}$ & $\begin{array}{l}20 \\
20\end{array}$ & $\begin{array}{l}32.50 \\
29.70\end{array}$ & 2.80 & $\begin{array}{l}3.63 \\
3.68\end{array}$ & 38 & 2.419 & .020 \\
\hline $\begin{array}{l}\text { Procedural } \\
\text { knowledge }\end{array}$ & $\begin{array}{l}\text { Experimental } \\
\text { Control }\end{array}$ & $\begin{array}{l}20 \\
20\end{array}$ & $\begin{array}{l}14.75 \\
14.60\end{array}$ & 1.30 & $\begin{array}{l}2.73 \\
2.16\end{array}$ & 38 & 1.668 & .103 \\
\hline $\begin{array}{r}\text { Conditional } \\
\text { knowledge }\end{array}$ & $\begin{array}{l}\text { Experimental } \\
\text { Control }\end{array}$ & $\begin{array}{l}20 \\
20\end{array}$ & $\begin{array}{l}19.80 \\
18.45\end{array}$ & 1.35 & $\begin{array}{l}3.18 \\
2.58\end{array}$ & 38 & 1.471 & .150 \\
\hline Planing & $\begin{array}{l}\text { Experimental } \\
\text { Control }\end{array}$ & $\begin{array}{l}20 \\
20\end{array}$ & $\begin{array}{l}26.10 \\
23.95\end{array}$ & 2.15 & $\begin{array}{l}3.76 \\
4.27\end{array}$ & 38 & 1.688 & .100 \\
\hline Monitoring & $\begin{array}{l}\text { Experimental } \\
\text { Control }\end{array}$ & $\begin{array}{l}20 \\
20\end{array}$ & $\begin{array}{l}27.85 \\
26.75\end{array}$ & 1.10 & $\begin{array}{l}4.73 \\
4.14\end{array}$ & 38 & .782 & .439 \\
\hline Evaluation & $\begin{array}{l}\text { Experimental } \\
\text { Control }\end{array}$ & $\begin{array}{l}20 \\
20\end{array}$ & $\begin{array}{l}22.50 \\
20.35\end{array}$ & 2.15 & $\begin{array}{l}3.36 \\
2.75\end{array}$ & 38 & 2.210 & .033 \\
\hline Debugging & $\begin{array}{l}\text { Experimental } \\
\text { Control }\end{array}$ & $\begin{array}{l}20 \\
20\end{array}$ & $\begin{array}{l}18.70 \\
17.35\end{array}$ & 1.35 & $\begin{array}{l}2.49 \\
3.24\end{array}$ & 38 & 1.474 & .149 \\
\hline $\begin{array}{l}\text { Information } \\
\text { management }\end{array}$ & $\begin{array}{l}\text { Experimental } \\
\text { Control }\end{array}$ & $\begin{array}{l}20 \\
20\end{array}$ & $\begin{array}{l}38.15 \\
32.05\end{array}$ & 6.10 & $\begin{array}{c}13.41 \\
4.76\end{array}$ & 38 & 1.916 & .063 \\
\hline Total & $\begin{array}{l}\text { Experimental } \\
\text { Control }\end{array}$ & $\begin{array}{l}20 \\
20\end{array}$ & $\begin{array}{l}200.35 \\
182.05\end{array}$ & 18.35 & $\begin{array}{l}28.06 \\
21.56\end{array}$ & 38 & 2.312 & .026 \\
\hline
\end{tabular}

A significant difference between the experimental and control groups was seen $(p=.026)$. When the results were examined according to the sub dimensions of the scale, there was a significant difference in evaluation $(p=.033)$ and declarative knowledge $(p=.020)$. 


\section{Comparison of The Control Group's Pre-test and Post-test Mean Scores Received from The MAI}

The second question of the study was to determine whether there was a significant difference in terms of metacognitive awareness between pre-test and post-test scores of the control group where the expository instruction method was applied. The results were given in Table 4.

Table 4

Comparison of The Control Group's Pre-Test and Post-Test Scores

\begin{tabular}{lcccccc}
\hline \multicolumn{1}{c}{ Sub-dimensions } & $n$ & Mean difference & $S D$ & $d f$ & $t$ & $p$ \\
\hline Declarative knowledge & 20 & -1.00 & 5.07 & 19 & -.881 & .390 \\
Procedural knowledge & 20 & 1.15 & 2.56 & 19 & 2.00 & .159 \\
Conditional knowledge & 20 & .90 & 3.22 & 19 & 1.247 & .227 \\
Planing & 20 & .90 & 5.65 & 19 & .712 & .485 \\
Monitoring & 20 & .35 & 5.70 & 19 & .274 & .787 \\
Evaluation & 20 & .65 & 3.70 & 19 & .785 & .442 \\
Debugging & 20 & .75 & 3.20 & 19 & 1.045 & .309 \\
Information management & 20 & .05 & 5.32 & 19 & .042 & .967 \\
Total & 20 & 3.75 & 25.89 & 19 & .648 & .525 \\
\hline
\end{tabular}

When pre-test and the post-test scores and mean values of the control group were examined, no significant differences were identified $(p=.525)$. According to this finding, there was no change in the total scores of the scale after the implementation.

\section{Comparison of The Experimental Group's Pre-test and Post-test Mean Scores Received from The MAI}

The third question of the study was to determine whether there was a significant difference in terms of metacognitive awareness between pre-test and post-test scores of the experimental group, where the content of the course was organized to improve metacognitive awareness. The results were given in Table 5.

Table 5

Comparison of The Experimental Group's Pre-Test and Post-Test Scores

\begin{tabular}{llccccc}
\hline \multicolumn{1}{c}{ Sub-dimensions } & $n$ & Mean difference & $S D$ & $d f$ & $t$ & $p$ \\
\hline Declarative knowledge & 20 & -1.75 & 4.66 & 19 & -1.67 & .110 \\
Procedural knowledge & 20 & -1.05 & 2.48 & 19 & -1.89 & .074 \\
Conditional knowledge & 20 & -1.15 & 3.43 & 19 & -1.49 & .151 \\
Planing & 20 & -2.25 & 4.35 & 19 & -2.31 & .032 \\
Monitoring & 20 & -.150 & 5.44 & 19 & -.12 & .903 \\
Evaluation & 20 & -1.05 & 5.27 & 19 & -.89 & .385 \\
Debugging & 20 & -1.00 & 5.01 & 19 & -.89 & .384 \\
Information management & 20 & -5.45 & 14.31 & 19 & -1.70 & .105 \\
Total & 20 & -13.85 & 32.107 & 19 & -1.93 & .069 \\
\hline
\end{tabular}

When the pre-test and post-test data of the experimental group were examined, it was seen that there was no significant difference in the total score received from the inventory $(p=.069)$. When the sub dimensions were examined to see whether there was a difference, a significant difference in planning was identified $(p=.032)$.

\section{Academic Achievement Level of Groups}

The last question to be answered in the study was whether there was a significant difference in academic achievement levels between the groups. The experimental group was where the course content was applied to improve metacognitive awareness, and the control group was where the exposity instruction method was applied.

Table 6

Course Success Level Between Groups

\begin{tabular}{lccccccc}
\hline \multicolumn{1}{c}{ Groups } & $n$ & $\bar{X}$ & Mean difference & $S D$ & $d f$ & $t$ & $p$ \\
\hline Experimental & 20 & 50.6 & \multirow{2}{*}{4.00} & 9.383 & \multirow{2}{*}{38} & \multirow{2}{*}{1.216} & .232 \\
Control & 20 & 46.6 & & 11.334 & & \\
\hline
\end{tabular}

For this purpose, an academic knowledge test was applied to both groups to determine the academic learning outcomes of the groups, and the midterm and final grades were compared using independent samples ttest. The mean values of the experimental group in the test were calculated as 50.6 while the mean values of the control group were calculated as 46.6, and the significance level was calculated $(p=.232)$ (Table 6). 


\section{Discussion}

The findings reveal that the course was carried out with activities organized to the improve the metacognitive awareness of special education teacher candidates in the experimental group when evaluated in terms of the total score obtained from MAI (Demiroğlu, 2008; Yokuş, 2009; Young \& Fry, 2008). When the groups evaluated within themselves in order to determine the change in the sub dimensions of the scale, there was a significant difference in dimension of planning in the experimental group.

When the experimental and control groups were compared with each other, there was a significant difference in total score, and the sub dimensions of the scale, along with declarative knowledge, and evaluation. It is believed that the reason for the difference in the declarative knowledge is due to the use of recalling and remembering activities. Both of these activities activated existing knowledge and awareness was supported. Adults, on the other hand, have great difficulties in clearly defining and using their own advanced cognition (Bereiter \& Scardamalia, 1993). For the reasons stated, other types of knowledge may not have been adequately and accurately expressed to teacher candidates.

The difference in the evaluation is thought to be due to the fact that the activities and strategies provided more benefit to learning by increasing the participation of the lesson and the effectiveness of the teaching. The findings indicate that the teacher candidates have also tried and developed the strategies in the course themselves. Research findings show that metacognitive strategies embedded in the content of the course in the field and the guidance provided for the use of these strategies contribute to setting goals for learning, planning, identifying additional problems, reviewing, and awareness (Vovides, 2005).

When the groups evaluated within themselves in order to determine the change in the sub dimensions of the scale, there was a significant difference in dimension of planning in the experimental group. Activities used in the lessons such as a chart, schematic regulator, graphic, question and answer activities were familiar to students. Among the behaviors that students are expected to realize and improve the learning goal in that course are the questions asked to activate preliminary knowledge at the beginning of the course and the attention and goal awareness activities that follow. Among the goals of brainstorming and peer activities are to discuss solutions to the problems and develop thinking skills. It is believed that these are the reasons for the difference determined in the sub-dimensions of planning and transactional information. For future research, it is recommended that these activities will be used for the development of planning and transactional knowledge.

When the level of academic achievement was examined, there was no difference between the two groups in terms of course success. One of the possible reasons for this result may be considered to be the way it measured success. Metacognition has characteristics that develop in the process and its effects on different areas can be evaluated depending on the process. The level of development and the way it displayed can also change with age and experience. In the study, the method of measuring success was performed using multiple choice questions developed by the researcher. For this reason, it may be better to choose multiple measurement and evaluation methods that are more suitable to the characteristics of the metacognition such as observation, portfolio, thinking logs.

One of the situations observed during the research was that students took photos rather than taking notes while commenting and describing it with their own expressions, charts, graphics, etc. Considering the characteristic of metacognition, such behaviors can be interpreted as the continuing the tendency of teacher candidates' to use what is available instead of structuring knowledge, even if their awareness increases. At this point, it is believed that technology also negatively affects the process. When the literature is examined, there are some findings that identify a positive relationship between teaching metacognitive strategy and self-regulation, and course success (Aktürk, 2010; Çalışkan, 2010; Jerkins, 2009; Park, 2000). There are some contrary findings reported as well (Aykut et al., 2016; Kimber, 2009; Sarıbaş, 2009).

The results of the study can also be discussed in terms of the approaches used in the improvement of metacognition. It is seen that in the studies for the improvement of metacognition, either strategy teaching or creating supportive social environments are adopted. It is very difficult to say which one is more efficient in the application area / classroom environment. The focus of discussions on this issue is that if it is not supported by the social environment, it will be difficult for individuals to practice metacognitive reflection (Brown \& Campione, 1996; Lin, 2001). Creating social environments and learning culture that supports metacognitive knowledge, skill and awareness in schools is among the responsibility areas of teachers. This emphasizes once again the importance of metacognition in the area of teacher training and competencies.

The results indicate that there is not enough improvement in teacher candidates' metacognitive awareness when no intervention is made and they are limited in acquiring and developing these skills. Strategy trainings and supportive 
social environments designed by metacognitive activities should also be added when educating teachers in the preservice period. Creating a curriculum by considering the individual's academic and social backgraund in the process can be a solution against the problems and limitations (Stein \& Markus, 1996).

In current programs, it is not considered sufficiently whether the teacher candidate adopts these roles that are expected of him or her; despite the revisions, as stated by Brown (1977), lecturers teach as they are used to or preference. They believe that completing courses in a specified time, with a specified success, is sufficient to train teacher candidates. Therefore, giving up their habits and questioning their own competence in terms of learning and teaching skills; using the methods, techniques and strategies they describe in the lessons themselves during the lectures can be a beginning for this. In the regulations made by Council of Higher Education (2011) and Ministry of National Education (2017) on vocational qualifications, skills such as self-assessment and self-regulation are stated as a requirement. Therefore, it is necessary to make the arrangements to meet the defined functional competencies and to develop alternative evaluation ways to meet these competencies during the selection and appointment of teacher candidates.

\section{Author's Contributions}

The subject of the research, research design, the data collection and the working group were decided together by the authors. The Success test was prepared by the first author. For using of the Metacognitive Awareness Inventory, permission was obtained by the first author from the researcher who adapted the inventory into Turkish. Editing the course content, writing the topics, preparing the activities, writing the processes were done by the first author. The feedback was received from the second author and corrections were made. During the reporting, the first author received feedback from the second author and edited the text.

\section{Acknowledgment}

I'm grateful to Assist. Prof. Çı̆̆ıl Aykut for her support at every stage of the research. 